NBER WORKING PAPER SERIES

\title{
DATING BUSINESS CYCLE TURNING POINTS
}

\author{
Marcelle Chauvet \\ James D. Hamilton \\ Working Paper 11422 \\ http://www.nber.org/papers/w11422 \\ NATIONAL BUREAU OF ECONOMIC RESEARCH \\ 1050 Massachusetts Avenue \\ Cambridge, MA 02138 \\ June 2005
}

This research is supported by the NSF under Grant No. NSF-0215754. This research is the work of the authors alone and should not be interpreted as the opinions, findings, or procedures of the National Bureau of Economic Research's Business Cycle Dating Committee. The views expressed herein are those of the author(s) and do not necessarily reflect the views of the National Bureau of Economic Research.

(O)2005 by Marcelle Chauvet and James D. Hamilton. All rights reserved. Short sections of text, not to exceed two paragraphs, may be quoted without explicit permission provided that full credit, including $($ ) notice, is given to the source. 
Dating Business Cycle Turning Points

Marcelle Chauvet and James D. Hamilton

NBER Working Paper No. 11422

June 2005

JEL No. E32

\begin{abstract}
$\underline{\text { ABSTRACT }}$
This paper discusses formal quantitative algorithms that can be used to identify business cycle turning points. An intuitive, graphical derivation of these algorithms is presented along with a description of how they can be implemented making very minimal distributional assumptions. We also provide the intuition and detailed description of these algorithms for both simple parametric univariate inference as well as latent-variable multiple-indicator inference using a state-space Markov-switching approach. We illustrate the promise of this approach by reconstructing the inferences that would have been generated if parameters had to be estimated and inferences drawn based on data as they were originally released at each historical date. Waiting until one extra quarter of GDP growth is reported or one extra month of the monthly indicators released before making a call of a business cycle turning point helps reduce the risk of misclassification. We introduce two new measures for dating business cycle turning points, which we call the "quarterly real-time GDPbased recession probability index" and the "monthly real-time multiple-indicator recession probability index" that incorporate these principles. Both indexes perform quite well in simulation with real-time data bases. We also discuss some of the potential complicating factors one might want to consider for such an analysis, such as the reduced volatility of output growth rates since 1984 and the changing cyclical behavior of employment. Although such refinements can improve the inference, we nevertheless find that the simpler specifications perform very well historically and may be more robust for recognizing future business cycle turning points of unknown character.

Marcelle Chauvet Department of Economics University of California, Riverside chauvet@ucr.edu

James D. Hamilton

Department of Economics, 0508

University of California, San Diego

9500 Gilman Drive

La Jolla, CA 92093-0508

and NBER

jhamilton@ucsd.edu
\end{abstract}




\section{Introduction}

The National Bureau of Economic Research (NBER) is a private research organization that, among other activities, identifies dates at which the U.S. would be said to be experiencing an economic recession. ${ }^{1} \quad$ These dates, reported at http://www.nber.org/cycles/cyclesmain.html, are regarded as authoritative by both academic researchers and the public at large.

For example, in July, 2003, the NBER announced that the most recent recession had finally ended. Remarkably, what the NBER announced in July, 2003 was that the recession had actually ended in November, 2001. There had been a similar two-year delay in the previous recession, for which the NBER announced in December, 1992 that the recession had ended in March, 1991.

These quasi-official dates are the outcome of discussions of the NBER's Business Cycle Dating Committee, a group of highly respected academics who review a variety of economic indicators to form a qualitative judgment about the state of the economy. The delays are explained by the fact that the Committee wants to be quite confident about its assessment before making a public declaration. There is nevertheless a cost to this accuracy, in that many members of the public can continue to believe that the economy is in a recession long after a solid recovery is under way. For example, in the 1992 election, the opposition party declared that the U.S. was experiencing the worst economic downturn since the Great Depression. A look at most of the facts would lead one to dismiss this claim as political hyperbole. However, if it had been the case that the recession beginning in July 1990 was still persisting as of November 1992, as one might have legitimately inferred from the failure of the NBER to announce the recession as over, it indeed would have qualified as the longest economic downturn since the Depression. More recently, the widespread belief by the American public that the U.S. was still in recession in 2003 may have played a role in tax cuts approved by the U.S. Congress, the outcome of a special election for the governor of California, and a host of other policy and planning decisions by government bodies, private firms,

\footnotetext{
1 This research paper is the work of the authors alone and should not be interpreted as the opinions, findings, or procedures of the NBER's Business Cycle Dating Committee. The manner in which the NBER currently arrives at business cycle dates is described at http://www.nber.org/cycles/recessions.html.
} 
and individual households.

During the last decade, academic researchers have come to treat the question of whether the economy is experiencing a recession as a formal statistical issue rather than a subjective qualitative assessment. This approach started with Hamilton (1989) and has since been adopted in hundreds of academic studies. ${ }^{2} \quad$ Given the importance to the public at large of identifying where the economy is at any given point in time, it seems worthwhile to investigate whether these formal quantitative methods could be used to produce announcements that might be useful to the public in real time. The purpose of this chapter is to review the performance of several such methods. We begin in Section 2 with a background discussion of this approach in a very simple application that uses only data on U.S. real GDP growth and minimal distributional assumptions. In Section 3 we implement a parametric version of this approach to GDP data. Section 4 describes a method for combining the inference from a number of different economic indicators. ${ }^{3}$ Section 5 presents results from such multivariate inference, while Section 6 explores the robustness of these multivariate inferences to several alternative specifications. ${ }^{4}$

\section{What can we infer from U.S. GDP growth rates?}

Figure 1 plots quarterly growth rates (quoted at an annual rate) of U.S. real GDP since 1947, with dates of economic recessions as determined by the NBER indicated with shaded regions. Consider what we can say from this GDP data alone about the broad properties of NBER's classifications. Forty-five of the 229 quarters between 1947:II and 2004:II were classified as "recession" and the remaining 184 as "expansion." First consider the 45 recession quarters as representatives of a certain population, namely, what GDP growth looks like when the economy is in recession. The

\footnotetext{
${ }^{2}$ For some alternatives see Lundbergh and Terasvirta (2002), van Dijk, Terasvirta and Franses (2002), Harding and Pagan (2002) and Artis, Marcelino and Proietti (2004).

3 More specifically, we use a dynamic factor model with regime switching, as in Chauvet (1998), which is a nonlinear state space model. This class of models is very popular in several fields. Some of the important work in this area includes Gordon and Smith (1990), Carlin, Polson, and Stoffer (1992), Kitagawa (1987), Fridman and Harris (1998), Kim and Nelson (1999a), Durbin and Koopman (1997), among others.

4 A companion paper by Chauvet and Piger (2005) compares the results from the method described in Section 4 with mechanical business cycle dating rules proposed by Harding and Pagan (2002).
} 
average quarterly growth rate in recession is $-1.23 \%$ (expressed at an annual rate), with a standard deviation of 3.55. The top panel of Figure 2 plots a nonparametric kernel estimate of the density of these 45 quarters. ${ }^{5} \quad$ One is more likely to see GDP falling than rising during a recession, but this is by no means certain; in fact, 15 of the 45 recession quarters are associated with positive GDP growth.

[ insert Figure 1 about here ]

The bottom panel of Figure 2 plots the corresponding density for the 184 postwar quarters classified as economic expansion. These are characterized by a mean annualized growth rate of $4.49 \%$ with a standard deviation of 3.24 . This distribution is overwhelmingly dominated by positive growth rates, though there again is some small probability of observing a negative growth rate during what is considered to be an economic expansion.

[ insert Figure 2 about here ]

If one simply selects a postwar quarterly growth rate at random, there's a $20 \%$ probability it would be one of the 45 quarters classified as a recession and an $80 \%$ probability of falling in an expansion. The unconditional distribution of GDP growth rates can be viewed as a mixture of the two distributions in Figure 2. This mixture is represented in the top panel of Figure 3, in which the height of the long-dashed line is found by multiplying the height of the top panel of Figure 2 by 0.2. The short-dashed line represents 0.8 times the bottom curve of Figure 2. The sum of these two curves (the solid line in the top panel of Figure 3) represents the unconditional density of one quarter's growth rate without knowing whether or not the quarter would be classified as recession.

[ insert Figure 3 about here ]

From the top panel of Figure 3, one could make an intelligent prediction as to what classification NBER will eventually arrive at (expansion or recession) as soon as the GDP figures are released.

\footnotetext{
5 This was calculated using the "density" command in RATS with a Gaussian kernel and bandwidth set equal to 3 .
} 
If GDP falls by more than $6 \%$, most of the height of the solid line is coming from the long-dashed density, suggesting that it is overwhelmingly likely that the quarter will be classified as recession. If GDP rises by more than $6 \%$, almost none of the density comes from the short-dashed line, leading us to expect NBER to classify that quarter as expansion. Intuitively, we might use the ratio of the height of the long-dashed line to the height of the solid line as a measure of the likelihood that NBER would classify a quarter with GDP growth of an amount specified on the horizontal axis as being part of a recession. This ratio is plotted in the bottom panel of Figure 3 .

Using this ratio in this way is more than intuitively appealing. It turns out to be precisely an application of Bayes Law for this setting. Specifically, let $S_{t}=1$ if the NBER ends up classifying quarter $t$ as an expansion and $S_{t}=2$ if recession. Let $y_{t}$ denote the quarter $t$ GDP growth rate. Then $f\left(y_{t} \mid S_{t}=2\right)$ is the density of GDP growth rates in recession, a nonparametric estimate of which is given by the top panel of Figure 2, while the expansion density $f\left(y_{t} \mid S_{t}=1\right)$ corresponds to the bottom panel. Let $\operatorname{Pr}\left(S_{t}=2\right)=0.20$ be the probability that any given quarter is classified as recession. Bayes Law states that the probability that NBER will declare a recession given that the GDP growth for the quarter is known to be $y_{t}$ can be calculated from

$$
\operatorname{Pr}\left(S_{t}=2 \mid y_{t}\right)=\frac{f\left(y_{t} \mid S_{t}=2\right) \operatorname{Pr}\left(S_{t}=2\right)}{f\left(y_{t} \mid S_{t}=1\right) \operatorname{Pr}\left(S_{t}=1\right)+f\left(y_{t} \mid S_{t}=2\right) \operatorname{Pr}\left(S_{t}=2\right)} .
$$

But $f\left(y_{t} \mid S_{t}=2\right) \operatorname{Pr}\left(S_{t}=2\right)$ is simply the height of the long-dashed line in Figure 3, while $f\left(y_{t} \mid S_{t}=1\right) \operatorname{Pr}\left(S_{t}=1\right)$ is the height of the short-dashed line. Hence the ratio plotted in the bottom panel of Figure 3,

$$
\operatorname{Pr}\left(S_{t}=2 \mid y_{t}\right)=\frac{0.2 f\left(y_{t} \mid S_{t}=2\right)}{0.8 f\left(y_{t} \mid S_{t}=1\right)+0.2 f\left(y_{t} \mid S_{t}=2\right)},
$$

is indeed the optimal prediction $\operatorname{Pr}\left(S_{t}=2 \mid y_{t}\right)$ about what NBER will declare if the quarter's GDP growth is $y_{t}$.

Predicting NBER's declaration if we get growth rates as extreme as $\pm 6 \%$ is obviously quite robust and sensible. Unfortunately, it is not particularly useful, since the vast majority of GDP growth rates are not this extreme, and for typical data the prediction about what NBER will 
declare in the bottom panel of Figure 3 is not very precise. Fortunately, there is another piece of information about the NBER's classifications that can be extremely helpful here, which is the fact that the Committee usually makes the same declaration in $t+1$ that it made in $t$. Of the 45 quarters characterized as recession, 35 or $78 \%$ were followed by another quarter of recession. Of the 183 expansion quarters between 1947:II and 2004:I, 173 or 95\% were followed by another quarter of expansion.

Suppose we observe a particular GDP growth rate for quarter $t$ of $y_{t}$; perhaps this is a value like $y_{t}=-6$, which we are reasonably confident will be described as a recession. Given this information, the probability that next quarter $t+1$ will also be classified as a recession is no longer 0.20 but is much higher. Specifically,

$$
\begin{aligned}
\operatorname{Pr}\left(S_{t+1}=2 \mid y_{t}\right) & =\operatorname{Pr}\left(S_{t+1}=2 \mid S_{t}=2, y_{t}\right) \operatorname{Pr}\left(S_{t}=2 \mid y_{t}\right)+\operatorname{Pr}\left(S_{t+1}=2 \mid S_{t}=1, y_{t}\right) \operatorname{Pr}\left(S_{t}=1 \mid y_{t}\right) \\
& =0.78 \operatorname{Pr}\left(S_{t}=2 \mid y_{t}\right)+(1-0.95) \operatorname{Pr}\left(S_{t}=1 \mid y_{t}\right)
\end{aligned}
$$

where we've assumed that $\operatorname{Pr}\left(S_{t+1}=2 \mid S_{t}=2, y_{t}\right)=\operatorname{Pr}\left(S_{t+1}=2 \mid S_{t}=2\right)=0.78$. For example, if there was convincing evidence of a recession in period $t$ (say, $\operatorname{Pr}\left(S_{t}=2 \mid y_{t}\right)=0.9$ ), then the probability that we will still be in recession in $t+1$ would be $(0.78)(0.9)+(1-0.95)(1-0.9)=0.71$. If we then learn the quarter $t+1$ growth rate $y_{t+1}$ as well, the inference about $S_{t+1}$ is found not from the height of the bottom panel of Figure 3, but instead from a mixture whose recession probability is 0.71 rather than 0.20 , that is, equation (1) would be replaced with

$$
\begin{aligned}
\operatorname{Pr}\left(S_{t+1}=2 \mid y_{t+1}, y_{t}\right) & =\frac{f\left(y_{t+1} \mid S_{t+1}=2, y_{t}\right) \operatorname{Pr}\left(S_{t+1}=2 \mid y_{t}\right)}{\sum_{j=1}^{2} f\left(y_{t+1} \mid S_{t+1}=j, y_{t}\right) \operatorname{Pr}\left(S_{t+1}=j \mid y_{t}\right)} \\
& =\frac{0.71 f\left(y_{t+1} \mid S_{t+1}=2, y_{t}\right)}{0.29 f\left(y_{t+1} \mid S_{t+1}=1, y_{t}\right)+0.71 f\left(y_{t+1} \mid S_{t+1}=2, y_{t}\right)}
\end{aligned}
$$

If we assume that recessions are the only source of GDP dynamics, so that $f\left(y_{t+1} \mid s_{t+1}, y_{t}\right)=$ $f\left(y_{t+1} \mid s_{t+1}\right)$, we could again use the height of the top panel of Figure 2 at the given value of $y_{t+1}$ as our estimate of $f\left(y_{t+1} \mid S_{t+1}=2, y_{t}\right)$, in which case we just replace the mixture in the top panel of Figure 3 (which assumed a $20 \%$ weight on the recession density and $80 \%$ on the expansion 
density), with a mixture that puts $71 \%$ weight on the recession density and $29 \%$ on the expansion density, as in the top panel of Figure 4. The ratio of the height of the long-dashed curve to the solid curve in the top panel of Figure 4 gives the inference (2), plotted in the bottom panel of Figure 4. If we were reasonably confident that quarter $t$ was a recession, we are much more prone to call $t+1$ a recession as well.

[ insert Figure 4 about here ]

Another perspective on this form of inference is obtained as follows. Suppose that GDP growth for quarter $t$ is given by $y_{t}=y$, from which we calculate $\operatorname{Pr}\left(S_{t}=2 \mid y_{t}=y\right)$ as in the bottom panel of Figure 3. We can then use this magnitude $\operatorname{Pr}\left(S_{t}=2 \mid y_{t}=y\right)$ in place of the constant 0.20 to weight the recession distribution. The ratio of the heights of the recession curve to the combined distribution would then correspond to $\operatorname{Pr}\left(S_{t+1}=2 \mid y_{t+1}=y, y_{t}=y\right)$, that is, it is the probability of recession if we happened to observe GDP growth equal to $y$ for two quarters in a row. This quantity is plotted in the bottom panel of Figure 5, which is substantially steeper than the plot of $\operatorname{Pr}\left(S_{t+1}=2 \mid y_{t+1}=y\right)$ shown in the top panel. For example, if we had only a single quarter's observation of GDP, we would not have $50 \%$ confidence in predicting a recession unless GDP growth was below $-3.4 \%$. By contrast, two consecutive quarters GDP growth of $-1.8 \%$ would also give us $50 \%$ confidence that the economy had entered a recession.

[ insert Figure 5 about here ]

We could use the same principle to get a better picture of whether the economy was in a recession in quarter $t$ once we know the economic growth rate in quarter $t+1$. Specifically, we first make a prediction about both $S_{t}$ and $S_{t+1}$ based on $y_{t}$ alone,

$$
\operatorname{Pr}\left(S_{t+1}=j, S_{t}=i \mid y_{t}\right)=\operatorname{Pr}\left(S_{t+1}=j \mid S_{t}=i, y_{t}\right) \operatorname{Pr}\left(S_{t}=i \mid y_{t}\right)
$$


This magnitude can be calculated by multiplying $\operatorname{Pr}\left(S_{t}=i \mid y_{t}\right)$ by the appropriate constant:

$$
\operatorname{Pr}\left(S_{t+1}=j \mid S_{t}=i, y_{t}\right)=\left\{\begin{array}{ll}
0.95 & \text { if } i=1, j=1 \\
0.05 & \text { if } i=1, j=2 \\
0.22 & \text { if } i=2, j=1 \\
0.78 & \text { if } i=2, j=2
\end{array} .\right.
$$

We then use Bayes Law to update this joint inference based on observation of $y_{t+1}$ :

$$
\begin{aligned}
& \operatorname{Pr}\left(S_{t+1}=j, S_{t}=i \mid y_{t+1}, y_{t}\right) \\
= & \frac{\operatorname{Pr}\left(S_{t+1}=j, S_{t}=i \mid y_{t}\right) f\left(y_{t+1} \mid S_{t+1}=j, S_{t}=i, y_{t}\right)}{\sum_{i=1}^{2} \sum_{j=1}^{2} \operatorname{Pr}\left(S_{t+1}=j, S_{t}=i \mid y_{t}\right) f\left(y_{t+1} \mid S_{t+1}=j, S_{t}=i, y_{t}\right)}
\end{aligned}
$$

We can again estimate $f\left(y_{t+1} \mid S_{t+1}=j, S_{t}=i, y_{t}\right)$ by $f\left(y_{t+1} \mid S_{t+1}=j\right)$, that is, by the top panel of Figure 2 when $j=2$ and the bottom panel when $j=1$. The desired inference about the economy at date $t$ based on information observed at date $t+1$ is then

$$
\operatorname{Pr}\left(S_{t}=i \mid y_{t+1}, y_{t}\right)=\sum_{j=1}^{2} \operatorname{Pr}\left(S_{t+1}=j, S_{t}=i \mid y_{t+1}, y_{t}\right)
$$

We have thus seen how, given nonparametric knowledge of how the distribution of GDP growth is different between expansions and contractions,

$$
f\left(y_{t} \mid S_{t}=i\right) \quad \text { for } i=1,2
$$

of how frequently the economy stays in the same regime,

$$
\operatorname{Pr}\left(S_{t+1}=j \mid S_{t}=i\right) \text { for } i, j=1,2,
$$

and the approximation that the state of the economy (recession or expansion) is the only probabilistic link between one quarter and the next, ${ }^{6}$

$$
\operatorname{Pr}\left(S_{t+1}=j \mid S_{t}=i\right)=\operatorname{Pr}\left(S_{t+1}=j \mid S_{t}=i, S_{t-1}=k, \ldots, y_{t}, y_{t-1}, \ldots\right)
$$

\footnotetext{
${ }^{6}$ In the parametric application of this approach described in the next section, we tested this assumption by using several alternative specifications of the Markov switching model, including higher autoregressive processes or allowing the variance and mean to follow the same or distinct Markov processes. We find that the simplest representation describes the data quite well and is most robust on a recursive sample of real-time data.
} 


$$
f\left(y_{t+1} \mid S_{t+1}=j\right)=f\left(y_{t+1} \mid S_{t+1}=j, S_{t}=i, S_{t-1}=k, \ldots, y_{t}, y_{t-1}, \ldots\right),
$$

one can use knowledge of GDP growth rates through date $t$ to make a prediction about whether the economy is in recession at any date $\tau$,

$$
\operatorname{Pr}\left(S_{\tau}=i \mid y_{1}, y_{2}, \ldots, y_{t}\right)
$$

If $t=\tau$, these are referred to as the "filter probabilities", whereas when $t>\tau$ they are described as "smoothed probabilities."

\section{Parametric representation.}

Although it is interesting to know how to perform these calculations nonparametrically, this degree of generality is really not needed for the problem at hand, since it appears from Figure 2 that a Gaussian distribution works quite well to describe these densities. The fact that the recession distribution has a standard deviation very similar to that for the expansion distribution implies that we would also lose little by assuming that the two distributions differ only in their means and share the same standard deviation $\sigma$. The suggestion is then that we replace the arbitrary density $f\left(y_{t} \mid S_{t}=2\right)$ in the top panel of Figure 2 with the $N\left(\mu_{2}, \sigma^{2}\right)$ distribution,

$$
f\left(y_{t} \mid S_{t}=2\right)=\frac{1}{\sqrt{2 \pi} \sigma} \exp \left(\frac{-\left(y_{t}-\mu_{2}\right)^{2}}{2 \sigma^{2}}\right)
$$

where $\mu_{2}$, the mean growth rate in contractions, should be about -1.2 with $\sigma$ around 3.5. Likewise we could easily parameterize the bottom panel of Figure $2, f\left(y_{t} \mid S_{t}=1\right)$, with the $N\left(\mu_{1}, \sigma^{2}\right)$ density for $\mu_{1}=4.5$. Let $p_{11}$ denote the probability that the economy remains in expansion from one quarter to the next,

$$
p_{11}=\operatorname{Pr}\left(S_{t+1}=1 \mid S_{t}=1\right),
$$

and $p_{22}$ the analogous probability for recessions:

$$
p_{22}=\operatorname{Pr}\left(S_{t+1}=2 \mid S_{t}=2\right) .
$$


Again the historical experience would lead us to expect that $p_{11}=0.95$ and $p_{22}=0.78$. Let $\boldsymbol{\theta}=\left(\mu_{1}, \mu_{2}, \sigma, p_{11}, p_{22}\right)^{\prime}$ denote the various unknown parameters.

A two-state Markov chain with transition probabilities $p_{i i}$ has unconditional distribution given by $^{7}$

$$
\operatorname{Pr}\left(S_{t}=2\right)=\frac{1-p_{11}}{2-p_{11}-p_{22}}=\pi_{2}
$$

The likelihood of the first observation in the sample $\left(y_{t}\right.$ for $\left.t=1\right)$ is then given by the mixture

$$
f\left(y_{1} ; \boldsymbol{\theta}\right)=\sum_{i=1}^{2} \frac{\pi_{i}}{\sqrt{2 \pi} \sigma} \exp \left(\frac{-\left(y_{1}-\mu_{i}\right)^{2}}{2 \sigma^{2}}\right)
$$

which is simply a parametric expression for the calculations that produced the solid curve in the top panel of Figure 3. The filtered probability for the first observation is

$$
\operatorname{Pr}\left(S_{1}=i \mid y_{1} ; \boldsymbol{\theta}\right)=\left[f\left(y_{1} ; \boldsymbol{\theta}\right)\right]^{-1} \frac{\pi_{i}}{\sqrt{2 \pi} \sigma} \exp \left(\frac{-\left(y_{1}-\mu_{i}\right)^{2}}{2 \sigma^{2}}\right)
$$

as in the bottom panel of Figure 3.

These probabilities in turn imply a predicted probability for the second observation of

$$
\operatorname{Pr}\left(S_{2}=j \mid y_{1} ; \boldsymbol{\theta}\right)=\sum_{i=1}^{2} p_{i j} \operatorname{Pr}\left(S_{1}=i \mid y_{1} ; \boldsymbol{\theta}\right) .
$$

The conditional likelihood of the second observation is given by the mixture whose weights are the predicted probabilities from (8),

$$
f\left(y_{2} \mid y_{1} ; \boldsymbol{\theta}\right)=\sum_{j=1}^{2} \frac{1}{\sqrt{2 \pi} \sigma} \exp \left(\frac{-\left(y_{2}-\mu_{j}\right)^{2}}{2 \sigma^{2}}\right) \operatorname{Pr}\left(S_{2}=j \mid y_{1} ; \boldsymbol{\theta}\right),
$$

or the kind of calculation that produced the solid curve in the top panel of Figure 4. From this we obtain as in the bottom panel of Figure 4 the filtered probabilities for the second observation,

$$
\operatorname{Pr}\left(S_{2}=i \mid y_{2}, y_{1} ; \boldsymbol{\theta}\right)=\left[f\left(y_{2} \mid y_{1} ; \boldsymbol{\theta}\right)\right]^{-1} \frac{1}{\sqrt{2 \pi} \sigma} \exp \left(\frac{-\left(y_{2}-\mu_{i}\right)^{2}}{2 \sigma^{2}}\right) \operatorname{Pr}\left(S_{2}=i \mid y_{1} ; \boldsymbol{\theta}\right),
$$

and predicted probabilities for the third:

$$
\operatorname{Pr}\left(S_{3}=j \mid y_{2}, y_{1} ; \boldsymbol{\theta}\right)=p_{i j} \operatorname{Pr}\left(S_{2}=i \mid y_{2}, y_{1} ; \boldsymbol{\theta}\right) .
$$

\footnotetext{
7 See for example Hamilton (1994, p. 683).
} 
Iterating in this fashion we obtain the log likelihood for the complete sample of observed GDP growth rates, $y_{1}, y_{2}, \ldots, y_{T}$, as a function of the parameter vector $\boldsymbol{\theta}$ :

$$
\log f\left(y_{1} ; \boldsymbol{\theta}\right)+\sum_{t=2}^{T} \log f\left(y_{t} \mid y_{t-1}, y_{t-2}, \ldots, y_{1} ; \boldsymbol{\theta}\right) .
$$

We motivated this way of thinking about the data by taking the NBER's conclusions as given and trying to characterize what the NBER has done. ${ }^{8} \quad$ However, no aspect of the NBER's dating appears in the final result (11), which is solely a function of observed GDP growth rates and the unknown parameters $\boldsymbol{\theta}$. One could accordingly choose as an estimate of $\boldsymbol{\theta}$ the value that maximizes the sample log likelihood of GDP growth rates (11). This maximum likelihood estimate is compared with the values we would have expected on the basis of the NBER inferences in Table $1 .{ }^{9} \quad$ The two sets of parameter values, although arrived at by different methods, are remarkably similar. This similarity is very encouraging, for two different reasons. First, it enhances the intellectual legitimacy of the perspective that the economy can be classified as being in an expansion or recession at any point in time, and that whether or not the economy is in recession can account for much of the variability and serial dependence of GDP growth rates. We did not impose any kind of conditions on the two means $\mu_{1}$ and $\mu_{2}$, and one could imagine the data being better described by all sorts of choices, such as "very rapid growth" versus "normal growth", or "normal growth" versus "slow growth." Table 1 implies that, using just GDP data alone without any reference to what NBER may have said, we would come up with a very similar conceptual scheme to the one that economists and the NBER have traditionally relied on.

[ insert Table 1 about here ]

A second reason that the correspondence between the two columns in Table 1 is encouraging

\footnotetext{
8 An alternative approach developed by Bry and Boschan (1971) attempts to formalize and elaborate on the rule of thumb that two quarters of falling GDP constitute a recession. However, this rule of thumb does not describe the decisions of the NBER Business Cycle Dating Committee, which defines a recession as "a significant decline in economic activity spread across the economy, lasting more than a few months, normally visible in real GDP, real income, employment, industrial production, and wholesale-retail sales" (http://www.nber.org/cycles.html/). We view our approach, unlike Bry and Boschan, as a direct statistical formalization of the NBER's stated method for qualitative evaluation.

${ }^{9}$ Maximum likelihood estimates were found using the EM algorithm described in Hamilton (1990).
} 
is that it raises the promise that we might be able to use GDP growth rates alone to arrive at classifications in a more timely and objective fashion than the NBER. The top panel of Figure 6 plots the filtered recession probabilities $\operatorname{Pr}\left(S_{t}=2 \mid y_{t}, y_{t-1}, \ldots, y_{1} ; \hat{\boldsymbol{\theta}}\right)$ implied by the maximum likelihood estimate of the parameter vector $\boldsymbol{\theta}$. For any date $t$ this is the probability that the economy is in recession based on observations of GDP growth rates at the time. The dates of economic recessions as determined after the fact by NBER are indicated by shaded regions on the graph. It seems clear that the two methodologies are identifying the same series of events over the postwar period, with the filter probabilities rising above $75 \%$ at some point during every postwar recession and typically remaining below $30 \%$ in times of expansions. There are some minor differences, with the two consecutive quarters of falling GDP in 1947:II-III and the -1.9\% growth in 1956:I temporarily pushing the filter probabilities a little over $50 \%$ in episodes that the NBER did not characterize as recessions. Also, in the 1990-91 recession, the filter probabilities did not come back below 50\% until 1991:IV, although the NBER says that the recession ended in 1991:I. Overall, though, the correspondence seems quite strong.

[ insert Figure 6 about here ]

The bottom panel of Figure 6 plots the smoothed probabilities, for which the full sample of observations through 2004:II was used to form an inference about the state of the economy at any given date. Using the full sample substantially smooths out a number of the minor temporary blips evident in the filter estimates, and brings the 1947 and 1956 inferences just under 50\%, ever so slightly favoring the NBER final call. Dates at which recessions began and ended according to the NBER are compared with the dates for which the smoothed probabilities are above $50 \%$ in Table 2. The smoothed probabilities date the 1980 recession as beginning 3 quarters earlier than the date assigned by the NBER. The two methods never differ by more than a quarter for either the starting date or ending date for any other recession.

[ insert Table 2 about here ]

This suggests that using a mechanical algorithm to identify business cycle turning points holds 
considerable promise. However, even the filter probabilities in the top panel of Figure 6 do not accurately capture the predictions that one could actually make with this framework in real time, for two reasons. First, the complete sample of data through 2004 was used to estimate the values of the parameter vector $\boldsymbol{\theta}$. This perhaps is not an overwhelming concern, since, as we saw in Table 1, one would have arrived at very similar magnitudes for $\boldsymbol{\theta}$ just based on the properties that one expects expansions and recessions should have. The second, more serious, problem is that the GDP figures as originally released by the Bureau of Economic Analysis can differ substantially from the historical series now available.

Croushore and Stark (2003) have established that the second issue can be extremely important in practice, and have helped develop an extensive data set archived at the Federal Reserve Bank of Philadelphia (available at http://www.phil.frb.org/econ/forecast/reaindex.html). This data set includes the history of GDP values that would have actually been available to a researcher or forecaster at any given point in time. The database consists of one set of GDP levels for 1947:I1965:III that would have been reported as of the middle of 1965:IV, a second set of GDP levels for 1947:I-1965:IV reported as of the middle of 1966:I, and so on, ending with a data set of GDP levels from 1947:I-2004:II as reported in the middle of 2004:III, with the latter data set being the one on which Figure 6 was based. There are a few gaps in this series, such as resulted from the benchmark GDP revision released in 1992:I. As originally released this revision only went back to 1959:I rather than all the way to 1947:I. To construct the inferences reported below, we assume that a researcher in 1992:I had available the GDP figures for 1947:I-1958:IV that technically were not published until 1993:I.

For each date $T$ between 1968:II and 2004:II, we constructed the values for GDP growth for quarter $t$ that a researcher would have had available as of date $T+1$, denoted $y_{t}^{[T]}$, for $t=1947$ :II through $T$. We estimated the value $\hat{\boldsymbol{\theta}}^{[T]}$ that maximized the log likelihood of $\left\{y_{1}^{[T]}, y_{2}^{[T]}, \ldots, y_{T}^{[T]}\right\}$ and used this estimate to form inferences about the economy for each date $t$ between 1947:II and $T$. The last value for GDP growth in this sample, $y_{T}^{[T]}$, (for example, the value of GDP for 
2004:II as reported in 2004:III), is apt to be particularly noisy. Furthermore, there is a substantial gain in accuracy from using the one-quarter smoothed probability rather than the current filtered probability. For these reasons, one obvious way to reduce the risk of misclassification is to wait to make a real-time assessment of the state of the economy in 2004:I until the first estimate of 2004:II growth (and revised estimate of 2004:I growth) is released in August 2004.

The top panel of Figure 7 plots these real-time one-quarter-smoothed inferences $\operatorname{Pr}\left(S_{T-1}=\right.$ $\left.2 \mid y_{1}^{[T]}, y_{2}^{[T]}, \ldots, y_{T}^{[T]} ; \hat{\boldsymbol{\theta}}^{[T]}\right)$ as a function of $T-1$. The quality of the inference degrades a bit using real-time released data in place of the full revised data set as now available. In particular, successfully calling the end of the 1990-1991 recession would have been quite difficult with the data as actually released in 1992. Notwithstanding, the inference in each of the other recessions based on using real-time GDP estimates with one-quarter of smoothing seems to produce quite a satisfactory result overall.

[ insert Figure 7 about here ]

We will refer to the magnitude $q_{t}^{(q)}=100 \times \operatorname{Pr}\left(S_{t}=2 \mid y_{1}^{[t+1]}, y_{2}^{[t+1]}, \ldots, y_{t+1}^{[t+1]} ; \hat{\boldsymbol{\theta}}^{[t+1]}\right)$ as our "quarterly real-time GDP-based recession probability index," whose value represents an inferred probability (in percent) as to whether the economy was in a recession at date $t$ using the firstreported GDP growth for quarter $t+1$. The " $(q)$ " superscript indicates that the index is based on quarterly data, in contrast to the monthly index that is developed in Section 5 below. We are also interested in the possibility of rendering quasi-official pronouncements based on this index. For this purpose, it seems prudent to build in a bit of conservatism into any announced changes in the economy. Let $D_{t}^{(q)}=$ "expansion" if we are declaring the economy to have been in an expansion in quarter $t$ and $D_{t}^{(q)}=$ "recession" otherwise, where this declaration is intended as a qualitative summary of the information in $q_{t}^{(q)}$. If last quarter we had declared the economy to be in an expansion $\left(D_{t-1}^{(q)}=\right.$ "expansion"), then this quarter we propose to declare the same thing 
as long as the one-quarter-smoothed probability of expansion remains above $35 \%$ :

$$
D_{t}^{(q)}=\left\{\begin{array}{l}
\text { "expansion" if } D_{t-1}^{(q)}=\text { "expansion" and } q_{t}^{(q)} \leq 65 \\
\text { "recession" if } D_{t-1}^{(q)}=\text { "expansion" and } q_{t}^{(q)}>65
\end{array} .\right.
$$

Likewise, if last quarter we had declared the economy to be in a recession, then this quarter we will declare the same thing as long as the one-quarter-smoothed probability of recession remains above $35 \%$ :

$$
D_{t}^{(q)}=\left\{\begin{array}{l}
\text { "recession" if } D_{t-1}^{(q)}=\text { "recession" and } q_{t}^{(q)} \geq 35 \\
\text { "expansion" if } D_{t-1}^{(q)}=\text { "recession" and } q_{t}^{(q)}<35
\end{array} .\right.
$$

Table 3 reports values for our real-time GDP-based recession probability index $q_{t}^{(q)}$ along with the proposed announcement $D_{t}^{(q)}$ for each quarter. The algorithm does quite a satisfactory job of identifying the dates at which recessions began and ended. Its performance is compared with NBER news releases in Table 4. NBER would have beaten our mechanical algorithm by one quarter on two occasions, declaring the start of the 2001 recession and the end of the 1991 recession one quarter earlier than we would have. On two other occasions (the start of the 1990-91 recession and end of the 1979-1980 recession), the mechanical rule beat NBER by one quarter. Our algorithm also would have declared the start of the 1979-80 recession two quarters earlier, and end of the 2001 recession four quarters earlier than did NBER. In all the other episodes, the two approaches would have made the same announcement in the same historical quarter.

[ insert Table 3 about here ]

These calculations suggest that an algorithmically-based inference could do quite a satisfactory job of calling business cycle turning points in real time. Not only does its quantitative performance seem to be a little better than NBER's, but there is an added benefit of objectivity. Given the potential of recession pronouncements to influence elections and policy decisions, there is always a possibility that there could be pressure to delay or accelerate making a subjective declaration in order to try to influence these outcomes. Our approach, by contrast, is completely objective and its mechanical operation transparent and reproducible. 
[ insert Table 4 about here ]

Our approach does have an ambiguity that the NBER announcements lack, however, in that it highlights the uncertainty inherent in the enterprise and calls direct attention to the fact that sometimes the situation is very difficult to call one way or another (for example, when the recession probability index is near 50\%). We would suggest, however, that this is inherent in the nature of the question being asked, and that openly recognizing this ambiguity is intellectually more honest and accurate than trying to conceal it. As long as we take the view that an economic recession is a real, objective event that may or may not have accounted for the observed data, there will always be some uncertainty in determining when and if one actually occurred. For better or worse, an objective assessment of the state of the economy of necessity must communicate not just a judgment (expansion or recession), but also some information about how compelling that conclusion is, given the data. The combined information conveyed by our proposed measures $q_{t}$ and $D_{t}$ seems a very promising way to communicate this information.

\section{Using multiple indicators to identify turning points.}

One drawback of the GDP-based measure is that it is only available quarterly. Given the lags in data collection and revision, this introduces an inherent 5-month delay in reporting of the index. A variety of measures available on a monthly basis might be used to produce much better inferences. By modeling the behavior of a number of different variables simultaneously, we can capture pervasive cyclical fluctuations in various sectors of the economy. As recessions and expansions are caused by different shocks over time, the inclusion of different variables increases the ability of the model to represent and signal phases of the business cycle in the monthly frequency. In addition, the combination of variables reduces measurement errors in the individual series and, consequently, the likelihood of false turning point signals, which is particularly important when monthly data are used.

Certainly the NBER dating committee does not base its conclusions just on the behavior of 
quarterly GDP. Inspired by the seminal work of Burns and Mitchell (1946), the NBER Business Cycle Dating Committee today primarily looks at four key monthly indicators ${ }^{10}$, including the growth rates of manufacturing and trade sales (sales), total personal income less transfer payments (income), civilian labor force employed in nonagricultural industries (employment), and industrial production $(\mathrm{IP})$. Let $\mathbf{y}_{t}$ denote the $(4 \times 1)$ vector whose first element $y_{1 t}$ is sales growth, $y_{2 t}$ is income growth, $y_{3 t}$ is employment growth, and $y_{4 t}$ is IP growth. In this section, we show how one can adapt the method of the previous section to use all four variables to infer the state of the business cycle.

A simple vector generalization of the approach in the preceding section would be quite straightforward. We could simply posit that the vector $\mathbf{y}_{t}$ has one mean $\boldsymbol{\mu}^{(1)}$ in expansions and a second mean $\boldsymbol{\mu}^{(2)}$ in recessions, where we indicate the economic regime with a superscript, reserving subscripts in this section to denote individual elements of a vector or to indicate the value of a variable for a particular date $t$. For example, the first element of the vector $\boldsymbol{\mu}^{(2)}$ would denote the average growth rate of sales during a recession. If $\mathbf{H}$ denotes the variance-covariance matrix of these growth rates in either expansion or recession, then we could simply replace the scalar $N\left(\mu_{2}, \sigma^{2}\right)$ distribution in (6) with the vector $N\left(\boldsymbol{\mu}^{(2)}, \mathbf{H}\right)$ distribution,

$$
f\left(\mathbf{y}_{t} \mid S_{t}=2\right)=\frac{1}{(2 \pi)^{n / 2}}|\mathbf{H}|^{-1 / 2} \exp \left\{-(1 / 2)\left[\mathbf{y}_{t}-\boldsymbol{\mu}^{(2)}\right]^{\prime} \mathbf{H}^{-1}\left[\mathbf{y}_{t}-\boldsymbol{\mu}^{(2)}\right]\right\}
$$

where $n=4$ denotes the number of elements in the vector $\mathbf{y}_{t}$. In every formula where we previously had the scalar $f\left(y_{t} \mid S_{t}=j\right)$ we would now have the scalar $f\left(\mathbf{y}_{t} \mid S_{t}=j\right)$. For example, to calculate the probability of a recession given only GDP growth $y_{t}$ in Figure 3 we took the ratio of the height of two lines. In the vector case we would be taking the ratio of the height of

\footnotetext{
${ }^{10}$ In NBER's FAQ page on business cycle dating at http://www.nber.org/cycles/recessions.html\#faq, it is stated that "The committee places particular emphasis on two monthly measures of activity across the entire economy: (1) personal income less transfer payments, in real terms and (2) employment. In addition, the committee refers to two indicators with coverage primarily of manufacturing and goods: (3) industrial production and (4) the volume of sales of the manufacturing and wholesale-retail sectors adjusted for price changes. The committee also looks at monthly estimates of real GDP such as those prepared by Macroeconomic Advisers (see http://www.macroadvisers.com). Although these indicators are the most important measures considered by the NBER in developing its business cycle chronology, there is no fixed rule about which other measures contribute information to the process." We follow Chauvet (1998) in using civilian labor force in nonagricultural industries rather than employees on nonagricultural payrolls as used by NBER, for reasons detailed in Section 6 below.
} 
two multidimensional surfaces, where the ratio of $f\left(\mathbf{y}_{t} \mid S_{t}=2\right) \operatorname{Pr}\left(S_{t}=2\right)$ to the sum $\left[f\left(\mathbf{y}_{t} \mid S_{t}=\right.\right.$ 1) $\left.\operatorname{Pr}\left(S_{t}=1\right)+f\left(\mathbf{y}_{t} \mid S_{t}=2\right) \operatorname{Pr}\left(S_{t}=2\right)\right]$ would tell us the probability of a recession given that the vector of growth rates is observed to equal $\mathbf{y}_{t}$, a calculation that could be performed for any possible $\mathbf{y}_{t}$. In essence, we would be judging the probability of a recession by whether, taken as a group, the elements of $\mathbf{y}_{t}$ are closer to the values we typically associate with expansions, $\boldsymbol{\mu}^{(1)}$, or closer to the values we typically associate with recessions, $\boldsymbol{\mu}^{(2)}$, with closeness based on the respective values of $\left[\mathbf{y}_{t}-\boldsymbol{\mu}^{(j)}\right]^{\prime} \mathbf{H}^{-1}\left[\mathbf{y}_{t}-\boldsymbol{\mu}^{(j)}\right]$ for $j=1$ or 2 , but also taking into account how likely we expected an expansion or recession to be $\operatorname{Pr}\left(S_{t}=j\right)$ before seeing the data $\mathbf{y}_{t}$.

Though this would be one possibility, it is not the best way to approach monthly data, since our simplifying assumption in equation (5) that recessions account for all of the observed dynamic behavior of $\mathbf{y}_{t}$ is no longer a very good one when we get to these higher frequency, more detailed data. We therefore adopt a generalization of the above method which has the basic effect of allowing $\boldsymbol{\mu}^{(j)}$, the vector of growth rates that we expect when the economy is in regime $j$ at date $t$, to depend not just on the current regime $j$ but also on the previous economic regime $S_{t-1}=i$ as well as the whole history of previous values for $\mathbf{y}_{t-m}$. The same is potentially true for the variance-covariance matrix $\mathbf{H}$. Thus the general approach is based on a specification of

$$
\begin{aligned}
& f\left(\mathbf{y}_{t} \mid S_{t}=j, S_{t-1}=i, \mathbf{Y}_{t-1}\right) \\
= & \frac{1}{(2 \pi)^{n / 2}}\left|\mathbf{H}_{t}^{(i, j)}\right|^{-1 / 2} \exp \left\{-(1 / 2)\left[\mathbf{y}_{t}-\boldsymbol{\mu}_{t}^{(i, j)}\right]^{\prime}\left[\mathbf{H}_{t}^{(i, j)}\right]^{-1}\left[\mathbf{y}_{t}-\boldsymbol{\mu}_{t}^{(i, j)}\right]\right\}
\end{aligned}
$$

where $\mathbf{Y}_{t-1}$ denotes the history of observations obtained through date $t-1$ :

$$
\mathbf{Y}_{t-1}=\left(\mathbf{y}_{t-1}^{\prime}, \mathbf{y}_{t-2}^{\prime}, \ldots, \mathbf{y}_{1}^{\prime}\right)^{\prime}
$$

The dependence on both $S_{t}$ and $S_{t-1}$ presents no real problems. Rather than forming an inference in the form of a probability that the current regime $S_{t}=j$, we will be calculating a joint probability that $S_{t}=j$ and $S_{t-1}=i$,

$$
\operatorname{Pr}\left(S_{t}=j, S_{t-1}=i \mid \mathbf{Y}_{t}\right)
$$


Indeed, we already saw exactly how to do this in equation (3). Here we are basically calculating how close the various elements of $\mathbf{y}_{t}$ are to the corresponding elements of $\boldsymbol{\mu}_{t}^{(i, j)}$, that is, how close they are to what we would have predicted given that $S_{t}=j$ and $S_{t-1}=i$ and the past observations $\mathbf{y}_{t-m}$. The inference then favors those combinations $i, j$ with the best fit to $\mathbf{y}_{t}$, taking into account also how likely the combination $i, j$ was regarded to be before seeing $\mathbf{y}_{t}$.

The question then is what growth rates $\boldsymbol{\mu}_{t}^{(i, j)}$ we expect for $\mathbf{y}_{t}$ in different phases of the business cycle. We follow Chauvet (1998) and Kim and Nelson (1999a) in their specification of how a recession may affect different economic indicators at the same time.

Our basic assumption is that there exists an aggregate cyclical factor $F_{t}$ that evolves according to

$$
F_{t}=\alpha^{\left(S_{t}\right)}+\phi F_{t-1}+\eta_{t} \quad S_{t}=1,2
$$

where $\eta_{t} \sim N\left(0, \sigma_{\eta}^{2}\right)$ and $\alpha^{\left(S_{t}\right)}=\alpha^{(1)}$ when the economy overall is in an expansion $\left(S_{t}=1\right)$ and $\alpha^{\left(S_{t}\right)}=\alpha^{(2)}$ in contraction. Note that if $F_{t}$ corresponded to GDP growth, equation (14) would include the dynamic process assumed for quarterly recession dynamics in the previous section as a special case when $\phi=0$, with $\alpha^{(1)}$ then corresponding to $\mu_{1}$ (the mean growth rate in expansions) and $\alpha^{(2)}$ corresponding to $\mu_{2}$. When $\phi$ is a number greater than zero (but presumably less than unity), expression (14) also allows for serial correlation in growth rates even without a business cycle turning point, and implies that in an expansion, the aggregate factor eventually trends toward a growth rate of $\alpha^{(1)} /(1-\phi)$.

We assume that the growth rate of the $r$ th monthly indicator $y_{r t}$ is determined by the aggregate factor $F_{t}$ and an idiosyncratic factor $v_{r t}$,

$$
y_{r t}=\lambda_{r} F_{t}+v_{r t} \quad \text { for } r=1,2,3,4
$$

with $v_{r t}$ itself exhibiting $A R(1)$ dynamics: ${ }^{11}$

$$
v_{r t}=\theta_{r} v_{r, t-1}+\varepsilon_{r t} .
$$

\footnotetext{
${ }^{11}$ Residual diagnostics and likelihood ratio tests favor first-order autoregressive processes for both the disturbance terms and the dynamic factor.
} 
When the aggregate factor $F_{t}$ changes, this induces a change in each variable in $\mathbf{y}_{t}$, with the $r$ th series changing by $\lambda_{r} \Delta$ when the aggregate factor changes by $\Delta$; the bigger $\lambda_{r}$, the more series $r$ responds to these aggregate fluctuations. The $r$ th series also experiences shocks $v_{r t}$ that have no consequences for the variables in $\mathbf{y}_{t}$ other than $y_{r t}$.

We will continue to assume as in the preceding section that business cycle transitions are the outcome of a Markov chain that is independent of previous realizations: ${ }^{12}$

$$
\operatorname{Pr}\left(S_{t}=j \mid S_{t-1}=i, S_{t-2}=k, \ldots, \mathbf{Y}_{t-1}\right)=p_{i j}
$$

The above system can be cast as a Markov-switching state space representation such as those analyzed by Chauvet (1998) and Kim and Nelson (1999a). The key to such a representation is a state vector $\mathbf{f}_{t}$ which contains (along with the regime $S_{t}$ ) all the information needed to forecast any of the individual series in $\mathbf{y}_{t}$. For this set-up, the state vector is a $(5 \times 1)$ vector,

$$
\mathbf{f}_{t}=\left(F_{t}, v_{1 t}, v_{2 t}, v_{3 t}, v_{4 t}\right)^{\prime}
$$

whose dynamics are characterized by

$$
\left[\begin{array}{c}
F_{t} \\
v_{1 t} \\
v_{2 t} \\
v_{3 t} \\
v_{4 t}
\end{array}\right]=\left[\begin{array}{c}
\alpha^{\left(S_{t}\right)} \\
0 \\
0 \\
0 \\
0
\end{array}\right]+\left[\begin{array}{ccccc}
\phi & 0 & 0 & 0 & 0 \\
0 & \theta_{1} & 0 & 0 & 0 \\
0 & 0 & \theta_{2} & 0 & 0 \\
0 & 0 & 0 & \theta_{3} & 0 \\
0 & 0 & 0 & 0 & \theta_{4}
\end{array}\right]\left[\begin{array}{c}
F_{t-1} \\
v_{1, t-1} \\
v_{2, t-1} \\
v_{3, t-1} \\
v_{4, t-1}
\end{array}\right]+\left[\begin{array}{c}
\eta_{t} \\
\varepsilon_{1 t} \\
\varepsilon_{2 t} \\
\varepsilon_{3 t} \\
\varepsilon_{4 t}
\end{array}\right]
$$

or in matrix notation,

$$
\mathbf{f}_{t}=\alpha^{\left(S_{t}\right)} \mathbf{e}_{5}+\boldsymbol{\Phi} \mathbf{f}_{t-1}+\mathbf{a}_{t}
$$

where $\mathbf{e}_{5}=(1,0,0,0,0)^{\prime}$. We assume that the disturbances in $\mathbf{a}_{t}$ are uncorrelated with each other

\footnotetext{
12 We test for the number of states versus a linear version of the model using the approach described in Garcia (1998). Garcia uses the results from Hansen $(1993,1996)$, treating the transition probabilities as nuisance parameters to test regime switching models. We construct Garcia's test statistic and compare with the the critical values reported in his paper. The critical values are significantly smaller than the likelihood ratio test for the dynamic factor with Markov regime switching yielding some evidence in rejecting the one state null hypothesis.
} 
and uncorrelated across time:

$$
\mathbf{a}_{t} \mid \mathbf{a}_{t-1}, \mathbf{a}_{t-2}, \ldots, \mathbf{a}_{1}, S_{t}, S_{t-1}, \ldots \sim N(\mathbf{0}, \boldsymbol{\Omega})
$$

where $\Omega$ is a diagonal matrix.

The observed variables $\mathbf{y}_{t}$ are related to the state vector through the observation equation,

$$
\left[\begin{array}{l}
y_{1 t} \\
y_{2 t} \\
y_{3 t} \\
y_{4 t}
\end{array}\right]=\left[\begin{array}{ccccc}
\lambda_{1} & 1 & 0 & 0 & 0 \\
\lambda_{2} & 0 & 1 & 0 & 0 \\
\lambda_{3} & 0 & 0 & 1 & 0 \\
\lambda_{4} & 0 & 0 & 0 & 1
\end{array}\right]\left[\begin{array}{c}
F_{t} \\
v_{1 t} \\
v_{2 t} \\
v_{3 t} \\
v_{4 t}
\end{array}\right] .
$$

The $r$ th row of (18) just reproduces (15). Again (18) can be conveniently written in matrix form as

$$
\mathbf{y}_{t}=\Lambda \mathbf{f}_{t}
$$

The model also requires a normalization condition, because if we doubled the standard deviation of each element of $\mathbf{a}_{t}$ and halved the value of each $\lambda_{r}$, the implied observed behavior of $\mathbf{y}_{t}$ would be identical. Our benchmark model resolves this normalization by setting $\sigma_{\eta}^{2}$, the first element of $\Omega$, equal to unity.

Note that equations (14) through (16) imply

$$
y_{r t}=\lambda_{r}\left[\alpha^{\left(S_{t}\right)}+\phi F_{t-1}+\eta_{t}\right]+\theta_{r} v_{r, t-1}+\varepsilon_{r t}
$$

or

$$
y_{r t}=\mu_{r t}^{\left(S_{t}\right)}+\lambda_{r} \eta_{t}+\varepsilon_{r t}
$$

where

$$
\mu_{r t}^{\left(S_{t}\right)}=\lambda_{r}\left[\alpha^{\left(S_{t}\right)}+\phi F_{t-1}\right]+\theta_{r} v_{r, t-1}
$$

Equation (20) can be stacked into a vector for $r=1,2,3,4$ using the notation of (17) and (19),

$$
\mathbf{y}_{t}=\boldsymbol{\Lambda} \alpha^{\left(S_{t}\right)} \mathbf{e}_{5}+\mathbf{\Lambda} \boldsymbol{\Phi} \mathbf{f}_{t-1}+\Lambda \mathbf{a}_{t}
$$




$$
=\boldsymbol{\mu}_{t}^{\left(S_{t}\right)}+\boldsymbol{\Lambda} \mathbf{a}_{t}
$$

for

$$
\boldsymbol{\mu}_{t}^{\left(S_{t}\right)}=\alpha^{\left(S_{t}\right)} \boldsymbol{\Lambda} \mathbf{e}_{5}+\boldsymbol{\Lambda} \boldsymbol{\Phi} \mathbf{f}_{t-1}
$$

In other words,

$$
\mathbf{y}_{t} \mid S_{t}=j, \mathbf{f}_{t-1} \sim N\left(\boldsymbol{\mu}_{t}^{(j)}, \boldsymbol{\Lambda} \boldsymbol{\Omega} \boldsymbol{\Lambda}^{\prime}\right)
$$

If we observed $\mathbf{f}_{t-1}$, this distribution would play the role of the $N\left(\boldsymbol{\mu}_{t}^{(i, j)}, \mathbf{H}_{t}^{(i, j)}\right)$ distribution in (13), and indeed, would be a little simpler than the general case in that $\boldsymbol{\mu}_{t}^{(i, j)}$ would not depend on $i$ and $\mathbf{H}_{t}^{(i, j)}$ would not depend on $i, j$, or $t$. In this simple case, we see from (20) that $\mu_{r t}^{\left(S_{t}\right)}$, the growth rate we expect for $y_{r t}$ when $S_{t}=2$, would be the sum of: (a) $\lambda_{r} \alpha^{(2)}$ (the product of $\lambda_{r}$, the response of series $r$ to the aggregate factor, with $\alpha^{(2)}$, the contribution of a recession to the aggregate factor); (b) $\lambda_{r} \phi F_{t-1}$ (the product of $\lambda_{r}$ with $\phi F_{t-1}$, where $\phi F_{t-1}$ is our forecast of the non-recession component of the aggregate factor $F_{t}$ ); and (c) $\theta_{r} v_{r, t-1}$ (our expectation of $v_{r t}$, the factor that is unique to series $r) .{ }^{13}$

Unfortunately, using this framework is a little more complicated than this, because even if we knew for certain that $S_{t-1}=i$, and had observed the values of $\mathbf{y}_{t-1}, \mathbf{y}_{t-2}, \ldots, \mathbf{y}_{1}$, we still would not know the value $\mathbf{f}_{t-1}$. We could, however, use methods described below to form an estimate of it, denoted $\mathbf{f}_{t-1 \mid t-1}^{(i)}$ :

$$
\mathbf{f}_{t-1 \mid t-1}^{(i)}=E\left(\mathbf{f}_{t-1} \mid S_{t-1}=i, \mathbf{Y}_{t-1}\right)
$$

The true value $\mathbf{f}_{t-1}$ differs from this estimate by some error $\mathbf{h}_{t-1 \mid t-1}^{(i)}$ :

$$
\mathbf{f}_{t-1}=\mathbf{f}_{t-1 \mid t-1}^{(i)}+\mathbf{h}_{t-1 \mid t-1}^{(i)} .
$$

Suppose we approximate the distribution of this error with the Normal distribution:

$$
\mathbf{h}_{t-1 \mid t-1}^{(i)} \sim N\left(\mathbf{0}, \mathbf{P}_{t-1 \mid t-1}^{(i)}\right) .
$$

\footnotetext{
${ }^{13}$ Extensions of the model such as allowing for more than two regimes, time-varying transition probabilities, and different lags for the factors are straightforward extensions of the specification described here.
} 
The $r$ th diagonal element of $\mathbf{P}_{t-1 \mid t-1}^{(i)}$ would be small if we had a good inference about the value of $f_{r, t-1}$. Treating $\mathbf{f}_{t-1}$ as known corresponds to the special case when $\mathbf{P}_{t-1 \mid t-1}^{(i)}=\mathbf{0}$.

Imperfect inference about $\mathbf{f}_{t-1}$ affects our ability to forecast $\mathbf{f}_{t}$. Substituting (23) into (17),

$$
\begin{aligned}
\mathbf{f}_{t} & =\alpha^{\left(S_{t}\right)} \mathbf{e}_{5}+\boldsymbol{\Phi}\left[\mathbf{f}_{t-1 \mid t-1}^{(i)}+\mathbf{h}_{t-1 \mid t-1}^{(i)}\right]+\mathbf{a}_{t} \\
& =\alpha^{\left(S_{t}\right)} \mathbf{e}_{5}+\boldsymbol{\Phi} \mathbf{f}_{t-1 \mid t-1}^{(i)}+\mathbf{q}_{t \mid t-1}^{(i)}
\end{aligned}
$$

where

$$
\begin{gathered}
\mathbf{q}_{t \mid t-1}^{(i)}=\boldsymbol{\Phi} \mathbf{h}_{t-1 \mid t-1}^{(i)}+\mathbf{a}_{t} \sim N\left(\mathbf{0}, \mathbf{Q}_{t \mid t-1}^{(i)}\right) \\
\mathbf{Q}_{t \mid t-1}^{(i)}=\boldsymbol{\Phi} \mathbf{P}_{t-1 \mid t-1}^{(i)} \boldsymbol{\Phi}^{\prime}+\boldsymbol{\Omega}
\end{gathered}
$$

with the last expression following from the definition of $\mathbf{P}_{t-1 \mid t-1}^{(i)}$ in (24) and the fact that $\mathbf{a}_{t}$ is independent of anything dated $t-1$ or earlier. Substituting (25) into (19),

$$
\mathbf{y}_{t}=\alpha^{\left(S_{t}\right)} \Lambda \mathbf{e}_{5}+\Lambda \mathbf{\Phi} \mathbf{f}_{t-1 \mid t-1}^{(i)}+\Lambda \mathbf{q}_{t \mid t-1}^{(i)} .
$$

Considering the case when $S_{t-1}=i$ and $S_{t}=j$, expression (27) implies that

$$
\mathbf{y}_{t} \mid S_{t}=j, S_{t-1}=i, \mathbf{Y}_{t-1} \sim N\left(\boldsymbol{\mu}_{t \mid t-1}^{(i, j)}, \mathbf{H}_{t \mid t-1}^{(i)}\right)
$$

where

$$
\begin{gathered}
\boldsymbol{\mu}_{t \mid t-1}^{(i, j)}=\alpha^{(j)} \boldsymbol{\Lambda} \mathbf{e}_{5}+\boldsymbol{\Lambda} \boldsymbol{\Phi} \mathbf{f}_{t-1 \mid t-1}^{(i)} \\
\mathbf{H}_{t \mid t-1}^{(i)}=\boldsymbol{\Lambda} \mathbf{Q}_{t \mid t-1}^{(i)} \mathbf{\Lambda}^{\prime}
\end{gathered}
$$

Expression (28) is the generalization we sought in (13). In this case, the value we expect for $y_{r t}$ when $S_{t-1}=i$ and $S_{t}=2$ is the sum of: (a) $\lambda_{r} \alpha^{(2)}$, just as in the case when we regarded $\mathbf{f}_{t-1}$ as if known; (b) $\lambda_{r} \phi F_{t-1 \mid t-1}^{(i)}$ (the product of $\lambda_{r}$ with $\phi F_{t-1 \mid t-1}^{(i)}$, where $\phi F_{t-1 \mid t-1}^{(i)}$ is our expectation of the non-recession component of the aggregate factor $F_{t}$, with this expectation based on $F_{t-1 \mid t-1}^{(i)}$, which is where we thought the factor was at date $t-1$, given that $S_{t-1}=i$ ); and (c) $\theta_{r} v_{r, t-1 \mid t-1}^{(i)}$ (what we expect for the dynamic factor $v_{r t}$ that is unique to series $r$ based on where we thought the idiosyncratic factor was at $t-1)$. The variance of our error in forecasting $\mathbf{y}_{t}$, denoted $\mathbf{H}_{t \mid t-1}^{(i)}$, 
depends on the date because having a larger number of observations $\left\{\mathbf{y}_{1}, \mathbf{y}_{2}, \ldots, \mathbf{y}_{t-1}\right\}$ can help us to improve the accuracy of the inference $\mathbf{f}_{t-1 \mid t-1}^{(i)}$.

The one additional step necessary before proceeding on to observation $t+1$ is to update the inference $\mathbf{f}_{t-1 \mid t-1}^{(i)}$ to incorporate date $t$ 's information. This is accomplished through a device known as the Kalman filter. The basic idea is to use the known correlation between the new observation $\mathbf{y}_{t}$ and the unobserved magnitude $\mathbf{f}_{t}$ to revise the prediction of $\mathbf{f}_{t}$ that we would have made using $\mathbf{f}_{t-1 \mid t-1}^{(i)}$ alone. One could imagine doing this with a regression of $\mathbf{f}_{t}$ on $\mathbf{y}_{t}$ and $\mathbf{f}_{t-1 \mid t-1}^{(i)}$. Although we don't have any observations on $\mathbf{f}_{t}$ with which to perform such a regression, we know from the structure of the model what the regression coefficients would turn out to be if we had an infinite number of such observations. In the appendix we show that these ideal regression coefficients are given by

$$
\begin{aligned}
\mathbf{f}_{t \mid t}^{(i, j)} & =E\left(\mathbf{f}_{t} \mid S_{t}=j, S_{t-1}=i, \mathbf{Y}_{t}\right) \\
& =\alpha^{(j)} \mathbf{e}_{5}+\mathbf{\Phi} \mathbf{f}_{t-t \mid t-1}^{(i)}+\mathbf{Q}_{t \mid t-1}^{(i)} \mathbf{\Lambda}^{\prime}\left[\mathbf{H}_{t \mid t-1}^{(i)}\right]^{-1}\left[\mathbf{y}_{t}-\boldsymbol{\mu}_{t \mid t-1}^{(i, j)}\right]
\end{aligned}
$$

Expression (30) gives the inference about $\mathbf{f}_{t}$ given both $S_{t-1}=i$ and $S_{t}=j$ in addition to the observed data $\mathbf{y}_{t}, \mathbf{y}_{t-1}, \ldots, \mathbf{y}_{1}$. The inference conditioning only on the current regime $S_{t}=j$ is found from

$$
\begin{aligned}
\mathbf{f}_{t \mid t}^{(j)} & =E\left(\mathbf{f}_{t} \mid S_{t}=j, \mathbf{Y}_{t}\right) \\
& =\sum_{i=1}^{2} E\left(\mathbf{f}_{t} \mid S_{t}=j, S_{t-1}=i, \mathbf{Y}_{t}\right) \operatorname{Pr}\left(S_{t-1}=i \mid S_{t}=j, \mathbf{Y}_{t}\right) \\
& =\sum_{i=1}^{2} \mathbf{f}_{t \mid t}^{(i, j)} \operatorname{Pr}\left(S_{t-1}=i \mid S_{t}=j, \mathbf{Y}_{t}\right)
\end{aligned}
$$

The probability necessary to calculate this last magnitude can again be found from Bayes Law:

$$
\operatorname{Pr}\left(S_{t-1}=i \mid S_{t}=j, \mathbf{Y}_{t}\right)=\frac{\operatorname{Pr}\left(S_{t}=j, S_{t-1}=i \mid \mathbf{Y}_{t}\right)}{\operatorname{Pr}\left(S_{t}=j \mid \mathbf{Y}_{t}\right)}
$$

The appendix also shows that the population mean squared error of the inference (31) is given 
by

$$
\begin{aligned}
\mathbf{P}_{t \mid t}^{(i, j)} & =E\left\{\left[\mathbf{f}_{t}-\mathbf{f}_{t \mid t}^{(j)}\right]\left[\mathbf{f}_{t}-\mathbf{f}_{t \mid t}^{(j)}\right]^{\prime} \mid S_{t}=j, S_{t-1}=i, \mathbf{Y}_{t}\right\} \\
& =\mathbf{Q}_{t \mid t-1}^{(i)}-\mathbf{Q}_{t \mid t-1}^{(i)} \mathbf{\Lambda}^{\prime}\left[\mathbf{H}_{t \mid t-1}^{(i)}\right]^{-1} \boldsymbol{\Lambda} \mathbf{Q}_{t \mid t-1}^{(i)}+\left[\mathbf{f}_{t \mid t}^{(i, j)}-\mathbf{f}_{t \mid t}^{(j)}\right]\left[\mathbf{f}_{t \mid t}^{(i, j)}-\mathbf{f}_{t \mid t}^{(j)}\right]^{\prime}
\end{aligned}
$$

Again this is converted to a magnitude that only depends on $j$ from

$$
\begin{aligned}
\mathbf{P}_{t \mid t}^{(j)} & =E\left\{\left[\mathbf{f}_{t}-\mathbf{f}_{t \mid t}^{(j)}\right]\left[\mathbf{f}_{t}-\mathbf{f}_{t \mid t}^{(j)}\right]^{\prime} \mid S_{t}=j, \mathbf{Y}_{t}\right\} \\
& =\sum_{i=1}^{2} \mathbf{P}_{t \mid t}^{(i, j)} \operatorname{Pr}\left(S_{t-1}=i \mid S_{t}=j, \mathbf{Y}_{t}\right) .
\end{aligned}
$$

There is just one problem with this algorithm. We assumed in (24) that the date $t-1$ inference had an error with a Normal distribution, conditional on $S_{t-1}=i$. But when we sum the inferences over the two values of $i$ as in the last line of (31), this would produce not a Normal distribution but a mixture of Normals. The mean and variance of this distribution are correctly given by $\mathbf{f}_{t \mid t}^{(j)}$ and $\mathbf{P}_{t \mid t}^{(j)}$, and the updating rule in (30) can still be motivated as the population regression. But when $\mathbf{h}_{t-1 \mid t-1}^{(i)}$ is not Normal, the distribution in (28) is no longer exact but only an approximation. This approximation, suggested by Kim (1994), is certainly necessary, because without the summation in (31), the number of possibilities would end up cascading, with the inference about $\mathbf{f}_{T}$ depending on $S_{T}, S_{T-1}, \ldots, S_{1}$. Fortunately, experience has shown that approximating the mixture distribution with a Normal distribution works very well in practice and we seem to lose little when we adopt it. ${ }^{14}$

To summarize, our inference for the vector case is based on an iterative algorithm, calculated sequentially for $t=1,2, \ldots, T$. As a result of step $t-1$ of these calculations, we would have calculated the following three magnitudes:

$$
\begin{gathered}
\operatorname{Pr}\left(S_{t-1}=i \mid \mathbf{Y}_{t-1}\right) \\
\mathbf{f}_{t-1 \mid t-1}^{(i)}
\end{gathered}
$$

\footnotetext{
14 For example, Chauvet and Piger (2005) estimate the dynamic factor model with regime switching in real time using both Kim's algorithm and Bayesian estimation methods (see Shepard 1994, Albert and Chib 1993, or Kim and Nelson 1999a). The results obtained using these two methods were found to be very similar.
} 


$$
\mathbf{P}_{t-1 \mid t-1}^{(i)}
$$

At step $t$ we then calculate

$$
\begin{gathered}
\operatorname{Pr}\left(S_{t}=j, S_{t-1}=i \mid \mathbf{Y}_{t-1}\right)=p_{i j} \operatorname{Pr}\left(S_{t-1}=i \mid \mathbf{Y}_{t-1}\right) \\
\boldsymbol{\mu}_{t \mid t-1}^{(i, j)}=\alpha^{(j)} \boldsymbol{\Lambda} \mathbf{e}_{5}+\mathbf{\Lambda} \boldsymbol{\Phi} \mathbf{f}_{t-1 \mid t-1}^{(i)} \\
\mathbf{Q}_{t \mid t-1}^{(i)}=\mathbf{\Phi} \mathbf{P}_{t-1 \mid t-1}^{(i)} \boldsymbol{\Phi}^{\prime}+\boldsymbol{\Omega} \\
\mathbf{H}_{t \mid t-1}^{(i)}=\mathbf{\Lambda} \mathbf{Q}_{t \mid t-1}^{(i)} \boldsymbol{\Lambda}^{\prime}
\end{gathered}
$$

These magnitudes are then all we need to construct the density of the $t$ th observation given $S_{t-1}=i, S_{t}=j$

$$
\begin{aligned}
& f\left(\mathbf{y}_{t} \mid S_{t-1}=i, S_{t}=j, \mathbf{Y}_{t-1}\right)= \\
& \frac{1}{(2 \pi)^{n / 2}}\left|\mathbf{H}_{t \mid t-1}^{(i)}\right|^{-1 / 2} \exp \left\{-(1 / 2)\left[\mathbf{y}_{t}-\boldsymbol{\mu}_{t \mid t-1}^{(i, j)}\right]^{\prime}\left[\mathbf{H}_{t \mid t-1}^{(i)}\right]^{-1}\left[\mathbf{y}_{t}-\boldsymbol{\mu}_{t \mid t-1}^{(i, j)}\right]\right\},
\end{aligned}
$$

the density not conditioning on $S_{t-1}$ or $S_{t}$,

$$
f\left(\mathbf{y}_{t} \mid \mathbf{Y}_{t-1}\right)=\sum_{i=1}^{2} \sum_{j=1}^{2} f\left(\mathbf{y}_{t} \mid S_{t-1}=i, S_{t}=j, \mathbf{Y}_{t-1}\right) \operatorname{Pr}\left(S_{t}=j, S_{t-1}=i \mid \mathbf{Y}_{t-1}\right)
$$

and the filter probability that $S_{t}=j$ :

$$
\operatorname{Pr}\left(S_{t}=j \mid \mathbf{Y}_{t}\right)=\sum_{i=1}^{2} \frac{f\left(\mathbf{y}_{t} \mid S_{t}=j, S_{t-1}=i, \mathbf{Y}_{t-1}\right) \operatorname{Pr}\left(S_{t}=j, S_{t-1}=i \mid \mathbf{Y}_{t-1}\right)}{f\left(\mathbf{y}_{t} \mid \mathbf{Y}_{t-1}\right)}
$$

This last calculation gives us the input (33) that we will need to proceed with the iteration for $t+1$. We update (34) by calculating

$$
\begin{gathered}
\operatorname{Pr}\left(S_{t-1}=i \mid S_{t}=j, \mathbf{Y}_{t}\right)=\frac{f\left(\mathbf{y}_{t} \mid S_{t}=j, S_{t-1}=i, \mathbf{Y}_{t-1}\right) \operatorname{Pr}\left(S_{t}=j, S_{t-1}=i \mid \mathbf{Y}_{t-1}\right)}{\sum_{i=1}^{2} f\left(\mathbf{y}_{t} \mid S_{t}=j, S_{t-1}=i, \mathbf{Y}_{t-1}\right) \operatorname{Pr}\left(S_{t}=j, S_{t-1}=i \mid \mathbf{Y}_{t-1}\right)} \\
\mathbf{f}_{t \mid t}^{(i, j)}=\alpha^{(j)} \mathbf{e}_{5}+\mathbf{\Phi} \mathbf{f}_{t-t \mid t-1}^{(i)}+\mathbf{Q}_{t \mid t-1}^{(i)} \mathbf{\Lambda}^{\prime}\left[\mathbf{H}_{t \mid t-1}^{(i)}\right]^{-1}\left[\mathbf{y}_{t}-\boldsymbol{\mu}_{t \mid t-1}^{(i, j)}\right] \\
\mathbf{f}_{t \mid t}^{(j)}=\sum_{i=1}^{2} \mathbf{f}_{t \mid t}^{(i, j)} \operatorname{Pr}\left(S_{t-1}=i \mid S_{t}=j, \mathbf{Y}_{t}\right) .
\end{gathered}
$$

Finally, we update the third input (35) from

$$
\mathbf{P}_{t \mid t}^{(i, j)}=\mathbf{Q}_{t \mid t-1}^{(i)}-\mathbf{Q}_{t \mid t-1}^{(i)} \mathbf{\Lambda}^{\prime}\left[\mathbf{H}_{t \mid t-1}^{(i)}\right]^{-1} \boldsymbol{\Lambda} \mathbf{Q}_{t \mid t-1}^{(i)}+\left[\mathbf{f}_{t \mid t}^{(i, j)}-\mathbf{f}_{t \mid t}^{(j)}\right]\left[\mathbf{f}_{t \mid t}^{(i, j)}-\mathbf{f}_{t \mid t}^{(j)}\right]^{\prime}
$$




$$
\mathbf{P}_{t \mid t}^{(j)}=\sum_{i=1}^{2} \mathbf{P}_{t \mid t}^{(i, j)} \operatorname{Pr}\left(S_{t-1}=i \mid S_{t}=j, \mathbf{Y}_{t}\right)
$$

Note that as a consequence of performing this iteration for $t=1,2, \ldots, T$, we have calculated the filter probabilities (37), one-month smoothed probabilities (38), and conditional density of the th observation (36). The latter can be used to construct the log likelihood for the entire sample,

$$
\ln f\left(\mathbf{Y}_{T}\right)=\ln f\left(\mathbf{y}_{1}\right)+\sum_{t=2}^{T} \ln f\left(\mathbf{y}_{t} \mid \mathbf{Y}_{t-1}\right) .
$$

The value obtained from (39) will depend on the values of the population parameters that were used to perform the above calculations. These consist of $\boldsymbol{\theta}=\left(\alpha^{(1)}, \alpha^{(2)}, p_{11}, p_{22}, \phi, \theta_{1}, \theta_{2}, \theta_{3}\right.$, $\left.\theta_{4}, \lambda_{1}, \lambda_{2}, \lambda_{3}, \lambda_{4}, \sigma_{\varepsilon_{1}}^{2}, \sigma_{\varepsilon_{2}}^{2}, \sigma_{\varepsilon_{3}}^{2}, \sigma_{\varepsilon_{4}}^{2}\right)^{\prime}$. We then choose values of these parameters so as to maximize the log likelihood (39).

All that is needed to implement the above procedure is the starting values of (33) through (35) for observation $t=1$, given initial values for $\boldsymbol{\theta}$. For the probabilities we use as initial condition the probabilities associated with the ergodic distribution of the Markov chain, $\operatorname{Pr}\left(S_{t-2}=h, S_{t-1}=\right.$ $\left.i \mid \mathbf{Y}_{t-1}\right)=\operatorname{Pr}\left(S_{0}=i\right)=\pi_{i}=\left(1-p_{j j}\right) /\left(2-p_{i i}-p_{j j}\right), i=1,2$, where $\pi_{i}$ is the ergodic probability. For the state vector, its unconditional mean and unconditional covariance matrix are used as initial values, that is, $\mathbf{f}_{0 \mid 0}^{(i)}=E\left(\mathbf{f}_{t}\right)$ and $\mathbf{P}_{0 \mid 0}^{(i)}=\mathbf{\Phi} \mathbf{P}_{0 \mid 0}^{(i)} \boldsymbol{\Phi}^{\prime}+\boldsymbol{\Omega} .^{15}$

\section{Empirical performance of the monthly recession proba- bility index.}

In this section we investigate the ability of the multivariate version of the Markov switching model in dating business cycle turning points at the monthly frequency. We used numerical search algorithms (e.g., Hamilton, 1994, Section 5.7) to find the value of the parameter vector $\hat{\boldsymbol{\theta}}$ that maximizes the log likelihood (39) of the observed historical sample of growth rates of sales, income, employment, and IP. These maximum likelihood estimates are reported in Table 5. For any date $t$ we can evaluate current filtered probabilities of expansions, $\operatorname{Pr}\left(S_{t}=1 \mid \mathbf{Y}_{t} ; \hat{\boldsymbol{\theta}}\right)$, and recessions,

${ }^{15}$ Since $\mathbf{f}_{t}$ is unobserved, we use the average of the unconditional mean of the four series in $\mathbf{Y}_{t}$. 
$\operatorname{Pr}\left(S_{t}=2 \mid \mathbf{Y}_{t} ; \hat{\boldsymbol{\theta}}\right)$, as calculated in equation (37) now based on the maximum likelihood estimate $\hat{\boldsymbol{\theta}}$. We can also construct a smoothed inference that uses both current and future observations of the series $\mathbf{y}_{t}$. For example, the conditional probability that the economy is in a recession at date $t$ based on all future observations of the series $\mathbf{y}_{t}$ is $\operatorname{Pr}\left(S_{t}=2 \mid \mathbf{Y}_{T} ; \hat{\boldsymbol{\theta}}\right)$.

[ insert Table 5 about here ]

As a first step in evaluating the ability of the model to reproduce the NBER dates, consider Figure 8, which plots the estimated full sample smoothed probabilities of recessions. The shaded areas represent periods dated as recessions by the NBER. The probabilities indicate that our model reproduces the NBER chronology very closely. During periods that the NBER classifies as expansions, the probabilities of recession are usually close to zero. At around the beginning of the NBER-dated recessions the probabilities rise and remain high until around the time the NBER dates the end of the recession. In particular, every time the probability of recession increases above $50 \%$, a recession follows. Conversely, the recession probabilities decrease below $50 \%$ at the recession trough.

[ insert Figure 8 about here ]

The model-based inferences about recession dates are compared with the dates determined by the NBER in Table 6 . The first column reports the month in which the recession started according to the NBER dates. The second column shows the first month in which the full sample smoothed probability of a recession rose above 50\%. The NBER recession dates and the model-based dates are very close, either exactly coinciding or differing by only one month. The one exception is the 2001 recession, in which the estimated probabilities started increasing in 2000, six months before the recession began as declared by the NBER. Our quarterly GDP-based full-sample inferences reported in Table 2 also suggested that this recession actually began in the fourth quarter of 2000 . Some special features of this recession will be discussed in more detail below in connection with data that would have actually been available in real time.

[ insert Table 6 about here ] 
The third column of Table 6 indicates the NBER date for the end of the recession, and the fourth column reports the last month for which the smoothed probability of a recession was above $50 \%$. Once again the model-based inference and the NBER dating for troughs are strikingly similar, even more so than for business cycle peaks.

These full sample smoothed probabilities are an important tool that can be used to revise historically the model assessment of business cycle phases. However, since these smoothed probabilities rely on future information $T-t$ steps ahead, they can not be used to evaluate the state of the business cycle on a current basis. In order to investigate the real-time performance of the multivariate Markov switching model for dating business cycles, two features should be taken into account that not even the use of current filtered probabilities would accomplish. First, only information available at the time the forecast is formed should be used. Thus, recursive estimation is applied to estimate the parameters of the model and infer the probabilities. Second, the real-time exercise needs to be implemented using only the same knowledge of data revisions that would have been available at the time. Thus, for each end of sample date in the recursive estimation the first release of the data that was available is used.

For each month between January 1978 and January 2004, we obtained values for the complete history of each of the four monthly variables in $\mathbf{y}_{t}$ going back to January 1959 , as that history would have been reported as of the indicated date. These data were assembled by hand from various issues of Business Conditions Digest and the Survey of Current Business, Employment and Earnings (both published monthly by the Bureau of Economic Analysis), and Economic Indicators (published monthly by the Council of Economic Advisers). As with our real-time GDP series described in Section 3, there were gaps in the full series for some vintages that were filled in with the next available observation. There were also occasionally large outliers, which were also replaced with the next release.

Using these data, we ran recursive estimations of the model starting with the sample from January 1959 to November 1977. The filter probability for the terminal date of this first data set, 
$\operatorname{Pr}\left(S_{t}=2 \mid \mathbf{y}_{1}^{[t]}, \mathbf{y}_{2}^{[t]}, \ldots, \mathbf{y}_{t}^{[t]} ; \hat{\boldsymbol{\theta}}^{[t]}\right)$ where $t$ corresponds to November 1977, is the first data point of the real-time filter probabilities corresponding to the single date $t$. We will refer below to 100 times this magnitude,

$$
p_{t}^{(m)}=100 \times \operatorname{Pr}\left(S_{t}=2 \mid \mathbf{y}_{1}^{[t]}, \mathbf{y}_{2}^{[t]}, \ldots, \mathbf{y}_{t}^{[t]} ; \hat{\boldsymbol{\theta}}^{[t]}\right)
$$

as our "preliminary monthly real-time recession probability index". The sample is then extended by one month, to December 1977, using now a completely new set of observations $\mathbf{y}_{1}^{[t+1]}, \mathbf{y}_{2}^{[t+1]}, \ldots, \mathbf{y}_{t+1}^{[t+1]}$ to come up with a new maximum likelihood estimate $\hat{\boldsymbol{\theta}}^{[t+1]}$ and a new terminal filter probability $\operatorname{Pr}\left(S_{t+1}=2 \mid \mathbf{y}_{1}^{[t+1]}, \mathbf{y}_{2}^{[t+1]}, \ldots, \mathbf{y}_{t}^{[t+1]} ; \hat{\boldsymbol{\theta}}^{[t+1]}\right)$ which will produce the preliminary index $p_{t+1}^{(m)}$ for date $t+1$. This procedure is repeated for each of the 315 recursive estimations until the final sample is reached, which extends from January 1959 to January 2004.

Notice that for each end of sample date in the recursive estimation procedure we use the first release of the data that was available for all four variables. The series employment and industrial production are more timely - they are released with only one month delay, whereas personal income and manufacturing and trade sales are released with a delay of two months. ${ }^{16}$ In order for the four real-time variables to enter the model estimation, we use the data vintage that contains the latest information on sales and personal income. For example, for the second sample from January 1959 to December 1977, we use the first release of data that included information on all four series for December 1977, which is February 1978.

Figure 9 plots the real-time recursive probability of a recession. Each point in the graph corresponds to a recursive estimation of real-time unrevised data, $p_{t}^{(m)} / 100$, plotted as a function of $t .{ }^{17}$ The probabilities match closely the NBER recessions, rising around the beginning of recessions and decreasing around their end. Once again, the probabilities remain below $50 \%$ during

\footnotetext{
16 The first releases of employment and industrial production for a given month are available, respectively, around the first and third weeks of the subsequent month, whereas the first releases of personal income and manufacturing and trade sales are available in the last week of the second month.

17 The values plotted in Figure 10 for dates $t$ before November 1977 are the filter probabilities from the sample of the first vintage, $\operatorname{Pr}\left(S_{t}=2 \mid \mathbf{y}_{1}^{(1977: 11)}, \mathbf{y}_{2}^{(1977: 11)}, \ldots, \mathbf{y}_{t}^{(1977: 11)} ; \hat{\boldsymbol{\theta}}^{(1977: 11)}\right)$.
} 
expansions, usually only rising beyond this threshold during recessions as dated by the NBER.

[ insert Figure 9 about here ]

The real-time recursive filtered probabilities are spikier than the filtered or smoothed probabilities obtained using revised data, which is expected given that unrevised data are generally noisier than revised releases. The real-time filtered probabilities are also intrinsically more noisy than their smoothed counterparts. We could immediately call a business cycle turning point if the real-time filtered probabilities move from below $50 \%$ to above $50 \%$ or vice versa. This rule maximizes the speed at which a turning point might be identified, but increases the chances of declaring a false positive. It seems more prudent to require confirmation of the turning point, by verifying it with more information As in Section 3, we investigate the gain in accuracy from using a low-order smoothed probability in addition to the current filtered probability. We combine the information on the readily available filtered probabilities with the more precise information obtained from $h$-step ahead (where $h$ is a low number) smoothed probabilities in real-time assessment of the business cycle phases. For example, the one-month ahead smoothed probabilities are used to create what we call our "revised monthly real-time recession probability index":

$$
q_{t}^{(m)}=100 \times \operatorname{Pr}\left(S_{t}=2 \mid \mathbf{Y}_{t+1}^{[t+1]} ; \hat{\boldsymbol{\theta}}^{[t+1]}\right)=\sum_{i=1}^{2} \operatorname{Pr}\left(S_{t}=2, S_{t+1}=i \mid \mathbf{Y}_{t+1}^{[t+1]} ; \hat{\boldsymbol{\theta}}^{[t+1]}\right) .
$$

Figure 10 displays real-time $h$-month-smoothed inferences for $h=1,2,3$. The shaded areas correspond to recessions as dated by the NBER. The quality of the inference in terms of accuracy improves as more information is used to form the smoothed probabilities. Figure 11 shows the realtime current filtered probabilities and the $h$-month-smoothed probabilities recession by recession. A distinct common pattern across the probabilities for the 1980, 1981, and 1990 recessions is that the current filtered probabilities declare the beginning of recessions a couple of months after the NBER says that a recession began, while they call the end of recessions at about the same time as the NBER dating. This is less accentuated for the 1980 and 1981 recessions than for the 1990 recession. The smoothed probabilities, however, increasingly adjust the date of recession peaks to 
earlier months, converging to a match to the NBER date. Regarding the end of recessions, the dates called by the current filtered probabilities for these recessions are timely with the NBER, and the smoothed probabilities obtained 1, 2, and 3 months later simply confirm these dates. Thus, there seems to be a gain in combining information from the current filtered probability and the smoothed probabilities in tabulating a chronology of expansion peaks in real time.

[ insert Figure 10 about here ]

[ insert Figure 11 about here ]

The inference from the multivariate Markov switching model for the 2001 recession is a bit distinct from previous downturns. The current filtered probabilities declare the beginning of the recession to have occurred at about the same time as the NBER date. The smoothed probabilities, however, increasingly adjust the peak date to a couple of months before the NBER date. We earlier observed the same thing with inferences based on quarterly GDP growth rates. In the case of the monthly index, these dynamics of the estimated probabilities are associated with the behavior of the growth rates of industrial production and personal income, which showed a decline already in 2000, before the recession had begun. The end of the 2001 recession is in accord with the NBER dating even when only the current filtered probabilities are used, as it is the case for previous recessions. However, this result for the last recession is sensitive to the choice of the employment series used in the estimation of the multivariate Markov switching model, as discussed in the next section.

While visual inspection of the probabilities yields some insight, it is difficult to ascertain how close the turning points determined by the multivariate model are to the NBER dates without compiling specific dates. In order to do this a formal definition is needed to convert the estimated probabilities into business cycle dates. We use a combination of the current filtered probabilities $p_{t}^{(m)}$ and one-month-smoothed probabilities $q_{t}^{(m)}$ to evaluate the performance of the multivariate Markov switching model in signalling business cycle turning points. We follow a similar rule to the one adopted for the univariate inference using real-time quarterly GDP, though there we only made 
use of the one-quarter smoothed probabilities $q_{t}^{(q)}$. Note that, just as we waited until one extra quarter's data on GDP growth $\left(y_{t+1}^{[t+1]}\right)$ becomes available before announcing the quarterly index $q_{t}^{(q)}$ for quarter $t$, we will require one extra month's data on sales, income, employment, and IP $\left(\mathbf{y}_{t+1}^{[t+1]}\right)$ before announcing the revised monthly index $q_{t}^{(m)}$ for month $t$. Let $D_{t}^{(m)}=$ "recession" if we declare the economy to have been in a recession in month $t$ and $D_{t}^{(m)}=$ "expansion" otherwise. If we had declared that the economy was in an expansion in month $t-1,\left(D_{t-1}^{(m)}=\right.$ "expansion"), then we would declare that a recession began in month $t$ only if (1) the filtered probability of recession at $t$ had risen above $65 \%$ (the preliminary index $p_{t}^{(m)}>65$ ) and $(2)$ this result is confirmed by the one-month ahead smoothed probability of expansion for assessment of the economy for that same month $t$ (the revised index $q_{t}^{(m)}>65$ ). Otherwise, we would declare the expansion to have continued through month $t$. Formally,

$$
D_{t}^{(m)}=\left\{\begin{array}{l}
\text { "expansion" if } D_{t-1}^{(m)}=\text { "expansion", and either } p_{t}^{(m)} \leq 65 \text { or } q_{t}^{(m)} \leq 65 \\
\text { "recession" if } D_{t-1}^{(m)}=\text { "expansion", and both } p_{t}^{(m)}>65 \text { and } q_{t}^{(m)}>65
\end{array} .\right.
$$

Similarly, if we had declared that the economy was in a recession in month $t-1$, then we would declare that a recovery began in month $t$ only if both the filtered and the one-month smoothed probabilities of recession for month $t$ are less than $35 \%$ :

$$
D_{t}^{(m)}=\left\{\begin{array}{l}
\text { "recession" if } D_{t-1}^{(m)}=\text { "recession", and either } p_{t}^{(m)} \geq 35 \text { or } q_{t+1 \mid t}^{(m)} \geq 35 \\
\text { "expansion" if } D_{t-1}^{(m)}=\text { "recession", and both } p_{t}^{(m)}<35 \text { and } q_{t+1 \mid t}^{(m)}<35
\end{array} .\right.
$$

The preliminary index $p_{t}^{(m)}$, revised index $q_{t}^{(m)}$, and announcement $D_{t}^{(m)}$ are reported in Table 7 .

\section{[ insert Table 7 about here ]}

Note that a more precise turning point signal comes at the expense of how quickly we would call it, since the timing when we would be able to make the announcement in real time would be delayed by one extra month. For example, for assessment of the current state of the economy at $t=1990: 7$, the first release of the real-time data for all four variables would be available in 1990:9. By using the one-month smoothed probability, we would have to wait until data released in 1990:10 to make a decision. Thus, there is a three-month delay in announcing turning points. 
We find that the gain in precision by using $q_{t}^{(m)}$ in addition to $p_{t}^{(m)}$ more than compensates the small loss in timing by one month.

Table 8 compares NBER news releases with the performance of the multivariate Markov switching model in dating and announcing business cycle chronology. Regarding dating the phases, the model would have made the identical declaration of the date of the 2001 business cycle peak as did the NBER, but lags the NBER dates by two or three months for the other three recessions. The difference between the model-based dates and the NBER's is smaller for troughs, coinciding in two occasions and differing by one or two months in the other two recessions.

[ insert Table 8 about here ]

The great advantage of the objective method regards the timely announcement of turning points. The algorithm does very well in announcing the beginning and end of downturns compared with statements released by the NBER. The model would have beaten the NBER in calling the beginning of a recession in two out of four occasions (the start of the 1990 and 2001 recessions, respectively) and would have coincided in two cases (the start of the 1980 and 1982 recessions). The advantage of the dates inferred from the multivariate model is even more significant for dating the end of recessions. The model beats the NBER announcements in all occasions, with leads from three to seventeen months. The model would have announced the end of the 1980 recession 8 months before the NBER's announcement, the end of the 1982 recession three months earlier than the NBER, the 1990 recession 17 months earlier, and the more recent recession in 2001 would have been declared to have ended 14 months before the announcement by the NBER.

Comparing the quarterly and monthly results, the multivariate Markov switching model and the univariate one applied to GDP usually convey similar information, but complement each other on some occasions. This indicates that there are clear gains in combining information from our quarterly real-time GDP-based recession probability index $\left(D_{t}^{(q)}\right.$ and $\left.q_{t}^{(q)}\right)$ and our monthly realtime multivariate-based recession probability indicators $\left(D_{t}^{(m)}, p_{t}^{(m)}\right.$, and $\left.q_{t}^{(m)}\right)$ in dating business cycle and announcing these dates in real time. For example, the quarterly real-time index dates 
the end of the 1990 recession only in the second quarter of 1992, and the announcement of this date would have been available in February 1993, three months after the NBER announcement. The monthly index, on the other hand, dates the end of this recession as March 1991, coinciding with the trough declared by the NBER. This date would have been available from the monthly index in July 1991, 17 months before the announcement by the NBER in December 1992. Regarding the 2001 recession, the monthly index dates the end of the 2001 recession in January 2002, two months after the trough in November 2001 declared by the NBER. The quarterly index, on the other hand, declares the end of this recession in the fourth quarter of 2001, coinciding with the NBER date. The monthly index would have announced this trough 14 months before the NBER declared the end of this recession, and the quarterly index would have announced it 12 months before.

In general, there is a gain in speed of announcement by using the monthly-based recession index, given that the monthly data are available more quickly than quarterly GDP mainly with respect to business cycle troughs. While the NBER's announcements sometimes beat the quarterly index, the monthly index consistently anticipates the recession end before the NBER's decisions. On the other hand, the monthly index (particularly if one relied only on $p_{t}^{(m)}$ or $q_{t}^{(m)}$ alone) shows more short-run volatility than does the quarterly index. Although combined inference is best, either index alone would have overall delivered more timely indications than did NBER in declaring the start or the end of the recessions in the real time sample, and the business cycle chronology obtained would have matched closely the NBER dating.

These results suggest that the algorithm-based inference contributes to the assessment of business cycle phases in real time, and offers quantitative improvements compared to the NBER methods. In addition, our approach is more objective and mechanical, which makes its potential use widespread. 


\section{Alternative approaches to monthly inference.}

In this section we report briefly on our investigations of some alternative specifications for the monthly index. We explored different autoregressive processes for the components of the state equation and tried specifications with one or two of the elements of $\mathbf{y}_{t}$ deleted or one or two other monthly series added. None of these changes seemed to make much difference for the inference.

One feature that does modify the results somewhat is the changing cyclical behavior of employment. In particular, the employment series used by the NBER, employees on non-agricultural payrolls (ENAP), displayed a very slow recovery in the last recession. In fact, real-time assessment of the recent economic recession using this series would have indicated that the downturn did not end until 2003. The real-time probabilities of recession obtained when this measure of employment is included in the estimation suggested that there was a slight recovery in economic activity from October 2001 to July 2002, but this was followed by a weakening of the economy in the subsequent months until early 2003. The use of this employment series also yields delays in signaling turning points for previous recessions. This is in agreement with Chauvet (1998), who found that this employment series lags the business cycles and documented the improvement in using alternative employment variables. Stock and Watson (1991) also found that payroll employment is a lagging indicator rather than a coincident variable of business cycle since its estimated residuals are serially correlated. For this reason, both Chauvet and Stock and Watson included lagged values for the factor in the measurement equation for payroll employment. On the other hand, this correction is not necessary when using other employment measurements.

Our analysis in Section 5 was instead based on an alternative employment series, Total Civilian Employment (TCE). This variable coincides with business cycle phases and delivers a much faster call of turning points in real time, as described in the previous section. The inclusion of this series allows us to keep the specification simple and yet robust to the use of real time data.

There are several reasons why these two series diverge sometimes, and a lot of controversy has 
emerged in the last few years on the best measure of employment. ENAP is based on a survey of business establishments, whereas TCE is based on a survey among households. These two employment series have generally moved together, with some minor differences around business cycle turning points until very recently. In particular, ENAP tends to overestimate employment around the beginning of recessions and underestimate around their end. As the results of estimation of our model based on the two different measures has reflected, these dynamics became very accentuated in the last recession in 2001. The main differences between these two series are that ENAP does not count agricultural and self-employed workers. More important, ENAP counts an individual twice if he or she works two jobs or changes jobs during the pay period. As a result of a debate regarding the sources of the differences, the Bureau of Labor and Statistics has produced some studies and concluded that a correction in population trend and addition of non-farmer workers in the TCE series would bring the two closer together in level and ex-post for the recent period (Di Natale, 2003; U.S. Department of Labor, 2004). This is also discussed in Juhn and Potter (1999). A comprehensive summary of these results and the debate can be found in Kane (2004).

However, the adjustment by BLS does not deal with the reliability and differences between these two series in real time, which is the focus of our analysis. The ENAP series only includes job destruction and creation with a lag, it does not include self-employment and contractors or off-the-books employment, and it double counts jobs if a person changes jobs within a payroll survey reference period. These can be very important cyclical factors around business cycle turning points. In particular, the first three differences can lead ENAP to signal a more severe recession and delay detection of a recovery, while the fourth one can overestimate employment around peaks. In addition, the first release of ENAP is preliminary and undergoes substantial revisions in subsequent months. There is also a significant revision of this series once a year when the smaller initial sample collected is adjusted by using as a benchmark the universe count of employment derived from Unemployment Insurance tax records that almost all employers are 
required to file. These corrections make real-time data on ENAP very different from the revised versions. Thus, although the revised ENAP may reflect better labor conditions ex-post, its performance in capturing real time cyclical changes in the economy is meager compared to the household survey (TCE).

In addition, we have also examined the performance of the model when a break in volatility in 1984 is taken into account. Kim and Nelson (1999b), McConnell and Perez-Quiros (2000), and Chauvet and Potter (2001) have found that the US economy became more stable since this date, particularly the quarterly GDP series. When this feature is incorporated in the model the results improve substantially with respect to the last two recessions, which took place after the structural break in volatility. We have nevertheless chosen not to correct for the decrease in volatility in the US economy in order to keep the analysis simple and robust.

Different rules were also investigated to declare the beginning and end of recessions. The one chosen, as described in the previous section, was not the one that necessarily maximizes the precision or speed of business cycle signals, but the one that worked as well with both simple and more complicated specifications. That is, we have chosen the rule that gives us the most confidence that it will be robust in future applications. We are less interested in fine-tuning the improvement of the algorithm than in obtaining a specification and rules that have a better chance to work well in the future. For this reason our analysis employs the simpler specification, which does not make any allowance for changes in the variance of economic fluctuations over time.

Overall, most of the options we investigated would result in quite reasonable estimates. Our conclusion is nevertheless that the benchmark model and inference rules presented in Section 5 appear to be the most robust with respect to changes in specification and data revision, and therefore recommend them as likely to prove most reliable for analyzing data and recognizing the business cycle trends in an ever-changing economy. 


\section{Appendix}

Here we derive equations (30) and (32). Suppose we have vectors $\mathbf{z}$ and $\mathbf{y}$ which have mean zero and a joint Normal distribution. Then the expectation of $\mathbf{z}$ given $\mathbf{y}$ turns out to be ${ }^{18}$

$$
E(\mathbf{z} \mid \mathbf{x})=E\left(\mathbf{z x}^{\prime}\right)\left[E\left(\mathbf{x x}^{\prime}\right)\right]^{-1} \mathbf{x}
$$

which is just a population version of the familiar regression formula. The conditional variance is known to be

$$
E[\mathbf{z}-E(\mathbf{z} \mid \mathbf{x})][\mathbf{z}-E(\mathbf{z} \mid \mathbf{x})]^{\prime}=E\left(\mathbf{z z}^{\prime}\right)-E\left(\mathbf{z x}^{\prime}\right)\left[E\left(\mathbf{x x}^{\prime}\right)\right]^{-1} E\left(\mathbf{x z}^{\prime}\right) .
$$

To apply these formulas here, let $\mathbf{z}=\mathbf{f}_{t}-\alpha^{(j)} \mathbf{e}_{5}-\mathbf{\Phi} \mathbf{f}_{t-t \mid t-1}^{(i)}$ and $\mathbf{x}=\mathbf{y}_{t}-\boldsymbol{\mu}_{t \mid t-1}^{(i, j)}$, which both have mean zero conditional on $S_{t}=j, S_{t-1}=i, \mathbf{y}_{t-1}, \mathbf{y}_{t-2}, \ldots, \mathbf{y}_{1}$. The updated inference about $\mathbf{f}_{t}$ is then given by

$$
\begin{aligned}
& E\left[\mathbf{f}_{t}-\alpha^{(j)} \mathbf{e}_{5}-\mathbf{\Phi} \mathbf{f}_{t-t \mid t-1}^{(i)} \mid \mathbf{y}_{t} ; S_{t}=j, S_{t-1}=i, \mathbf{Y}_{t-1}\right] \\
= & E\left\{\left[\mathbf{f}_{t}-\alpha^{(j)} \mathbf{e}_{5}-\mathbf{\Phi} \mathbf{f}_{t-t \mid t-1}^{(i)}\right]\left[\mathbf{y}_{t}-\boldsymbol{\mu}_{t \mid t-1}^{(i, j)}\right]^{\prime} \mid S_{t}=j, S_{t-1}=i, \mathbf{Y}_{t-1}\right\} \times \\
& \left(E\left\{\left[\mathbf{y}_{t}-\boldsymbol{\mu}_{t \mid t-1}^{(i, j)}\right]\left[\mathbf{y}_{t}-\boldsymbol{\mu}_{t \mid t-1}^{(i, j)}\right]^{\prime} \mid S_{t}=j, S_{t-1}=i, \mathbf{Y}_{t-1}\right\}\right)^{-1}\left[\mathbf{y}_{t}-\boldsymbol{\mu}_{t \mid t-1}^{(i, j)}\right] .
\end{aligned}
$$

But notice from (25) and (27) that

$$
\begin{aligned}
& E\left\{\left[\mathbf{f}_{t}-\alpha^{(j)} \mathbf{e}_{5}-\mathbf{\Phi} \mathbf{f}_{t-t \mid t-1}^{(i)}\right]\left[\mathbf{y}_{t}-\boldsymbol{\mu}_{t \mid t-1}^{(i, j)}\right]^{\prime} \mid S_{t}=j, S_{t-1}=i, \mathbf{Y}_{t-1}\right\} \\
= & E\left\{\mathbf{q}_{t \mid t-1}^{(i)}\left[\mathbf{q}_{t \mid t-1}^{(i)}\right]^{\prime} \boldsymbol{\Lambda}^{\prime}\right\} \\
= & \mathbf{Q}_{t \mid t-1}^{(i)} \boldsymbol{\Lambda}^{\prime}
\end{aligned}
$$

for $\mathbf{Q}_{t \mid t-1}^{(i)}$ the variance of $\mathbf{q}_{t \mid t-1}^{(i)}$ defined in (26). Similarly from (28),

$$
E\left\{\left[\mathbf{y}_{t}-\boldsymbol{\mu}_{t \mid t-1}^{(i, j)}\right]\left[\mathbf{y}_{t}-\boldsymbol{\mu}_{t \mid t-1}^{(i, j)}\right]^{\prime} \mid S_{t}=j, S_{t-1}=i, \mathbf{Y}_{t-1}\right\}=\mathbf{H}_{t \mid t-1}^{(i)}
$$

Substituting (44) and (45) into (43),

$$
E\left[\mathbf{f}_{t}-\alpha^{(j)} \mathbf{e}_{5}-\mathbf{\Phi} \mathbf{f}_{t-t \mid t-1}^{(i)} \mid \mathbf{y}_{t} ; S_{t}=j, S_{t-1}=i, \mathbf{Y}_{t-1}\right]=\mathbf{Q}_{t \mid t-1}^{(i)} \mathbf{\Lambda}^{\prime}\left(\mathbf{H}_{t \mid t-1}^{(i)}\right)^{-1}\left[\mathbf{y}_{t}-\boldsymbol{\mu}_{t \mid t-1}^{(i, j)}\right],
$$

18 See for example Hamilton (1994, p. 102). 
which upon rearranging yields (30).

Similar calculations allow the updated variance to be found from (42):

$$
\begin{aligned}
& E\left\{\left[\mathbf{f}_{t}-\mathbf{f}_{t \mid t}^{(i, j)}\right]\left[\mathbf{f}_{t}-\mathbf{f}_{t \mid t}^{(i, j)}\right]^{\prime} \mid S_{t}=j, S_{t-1}=i, \mathbf{Y}_{t}\right\} \\
= & \mathbf{Q}_{t \mid t-1}^{(i)}-\mathbf{Q}_{t \mid t-1}^{(i)} \mathbf{\Lambda}^{\prime}\left[\mathbf{H}_{t \mid t-1}^{(i)}\right]^{-1} \boldsymbol{\Lambda} \mathbf{Q}_{t \mid t-1}^{(i)} .
\end{aligned}
$$

To relate this magnitude to that given in (32), notice that

$$
\begin{aligned}
\mathbf{P}_{t \mid t}^{(i, j)}= & E\left\{\left[\mathbf{f}_{t}-\mathbf{f}_{t \mid t}^{(j)}\right]\left[\mathbf{f}_{t}-\mathbf{f}_{t \mid t}^{(j)}\right]^{\prime} \mid S_{t}=j, S_{t-1}=i, \mathbf{Y}_{t}\right\} \\
= & E\left\{\left[\mathbf{f}_{t}-\mathbf{f}_{t \mid t}^{(i, j)}+\mathbf{f}_{t \mid t}^{(i, j)}-\mathbf{f}_{t \mid t}^{(j)}\right]\left[\mathbf{f}_{t}-\mathbf{f}_{t \mid t}^{(i, j)}+\mathbf{f}_{t \mid t}^{(i, j)}-\mathbf{f}_{t \mid t}^{(j)}\right]^{\prime} \mid S_{t}=j, S_{t-1}=i, \mathbf{Y}_{t}\right\} \\
= & E\left\{\left[\mathbf{f}_{t}-\mathbf{f}_{t \mid t}^{(i, j)}\right]\left[\mathbf{f}_{t}-\mathbf{f}_{t \mid t}^{(i, j)}\right]^{\prime} \mid S_{t}=j, S_{t-1}=i, \mathbf{Y}_{t}\right\} \\
& +\left[\mathbf{f}_{t \mid t}^{(i, j)}-\mathbf{f}_{t \mid t}^{(j)}\right]\left[\mathbf{f}_{t \mid t}^{(i, j)}-\mathbf{f}_{t \mid t}^{(j)}\right]^{\prime}
\end{aligned}
$$

where cross-product terms disappear from the last expression because $E\left\{\mathbf{f}_{t}-\mathbf{f}_{t \mid t}^{(i, j)} \mid S_{t}=j, \mathbf{Y}_{t}\right\}=$ $\mathbf{0}$ and $\left[\mathbf{f}_{t \mid t}^{(i, j)}-\mathbf{f}_{t \mid t}^{(j)}\right]$ is a deterministic function of $S_{t}=j, S_{t-1}=i, \mathbf{Y}_{t}$. Substituting (46) into (47) results in (32). 


\section{References}

Albert, J. and S. Chib (1993), Bayes inference via Gibbs sampling of autoregressive time series subject to Markov mean and variance shifts, Journal of Business and Economic Statistics 11:1-15.

Artis, M., Marcellino, M. and Proietti, T. (2004), Dating business cycles: A methodological contribution with an application to the euro area," Oxford Bulletin of Economics and Statistics $66: 537-574$.

Bry, G. and C. Boschan (1971), Cyclical Analysis of Times Series: Selected Procedures and Computer Programs (National Bureau of Economic Research, New York).

Burns, Arthur F., and Wesley C. Mitchell (1946), Measuring Business Cycles, (National Bureau of Economic Research, New York).

Carlin, Bradley.P., Nicholas G. Polson, and David S. Stoffer (1992), A Monte-Carlo approach to nonnormal and nonlinear state-space modeling, Journal of the American Statistical Association 87:493-500.

Chauvet, Marcelle (1998), An economic characterization of business cycle dynamics with factor structure and regime switches, International Economic Review, 39:969-996.

Chauvet, Marcelle, and Jeremy Piger (2005), The real-time performance of business cycle dating methods, Working paper, University of California, Riverside.

Chauvet, Marcelle, and Simon Potter (2001), Recent changes in the U.S. business cycle, The Manchester School, 69:481-508.

Croushore, Dean, and Tom Stark (2003), A real-time data set for macroeconomists: Does the data vintage matter?, Review of Economics and Statistics 85:605-617.

Diebold Francis X. and Glenn D. Rudebusch (1996), Measuring business cycles: A modern perspective, Review of Economics and Statistics 78:67-77.

Di Natale, Marisa L. (2003) Creating comparability in CPS employment series, U.S. Department of Labor, Bureau of Labor Statistics, at www.bls.gov/cps/cpscomp.pdf. 
Durbin, J. and S. J. Koopman (1997) Monte Carlo maximum likelihood estimation of nonGaussian state space model, Biometrika 84:669-684.

Fridman, M. and L. Harris (1998), A maximum likelihood approach for non-Gaussian stochastic volatility models, Journal of Business and Economic Statistics 16:284-291.

Garcia, R. (1998), Asymptotic null distribution of the likelihood ratio test in Markov switching models, International Economic Review 39:763-788.

Gordon, K. and A.F.M. Smith (1990), Modelling and monitoring biomedical time series, Journal of the American Statistical Association 85:328-337.

Hamilton, James D. (1989), A new approach to the economic analysis of nonstationary time series and the business cycle, Econometrica 57:357-384.

Hamilton, James D. (1990), Analysis of time series subject to changes in regime, Journal of Econometrics 45:357-384.

Hamilton, James D. (1994), Time Series Analysis, (Princeton University Press, Princeton).

Harding, D. and Pagan, A. (2002), Dissecting the cycle: a methodological investigation, Journal of Monetary Economics 49:365-381

Hansen, B. E. (1993) The likelihood ratio test under non-standard conditions: Testing the Markov trend model of GNP, in M.H. Pesaran and S. Potter, eds., Nonlinear Dynamics Chaos and Econometrics, (John Wiley \& Sons, New York) 53-73.

Hansen, B. E. (1996) Inference when a nuisance parameter is not identified under the null hypothesis, Econometrica 64:413-430.

Harding, Don and Adrian Pagan (2002), Synchronization of cycles, Working paper, Australian National University.

Harrison, P.J., and C.F. Stevens (1976), Bayesian forecasting, Journal of the Royal Statistical Society Series B 38:205-247.

Juhn, Chinhui and Simon Potter (1999), Explaining the recent divergence in payroll and household employment growth, Current Issues in Economics and Finance, Federal Reserve Bank 
of New York, December, 1-6.

Kane, Tim (2004), Diverging employment data: A critical view of the payroll survey, The Heritage Foundation Center for Data Analysis, CDA04-03, available at http://www.heritage.org/ Research/Labor/CDA04-03.cfm.

Kim, Chang-Jin (1994), Dynamic linear models with Markov-switching, Journal of Econometrics $60: 1-22$.

Kim, Chang-Jin and Charles R. Nelson (1999a), State-Space Models with Regime Switching, (MIT Press, Cambridge, MA).

Kim, Chang-Jin and Charles R. Nelson (1999b), Has the U.S. economy become more stable? A Bayesian approach based on a Markov-switching model of the business cycle, Review of Economics and Statistics 81:608-616.

Kitagawa, G. (1987), Non-Gaussian state-space modeling of nonstationary time series, Journal of the American Statistical Association 82:1032-63.

Lundbergh, S and T. Terasvirta (2002), Forecasting with smooth transition autoregressive models, in Michael P. Clements and David F. Hendry, eds., A Companion to Economic Forecasting, (Blackwell, Oxford) 485-509.

Mariano, R.S., and Y. Murasawa (2003), A new coincident index of business cycles based on monthly and quarterly series, Journal of Applied Econometrics 18:427-443.

Perez-Quiros, Gabriel, and Margaret McConnell (2000), Output fluctuations in the United States: What has changed since the early 1980's?, American Economic Review 90:1464-1476.

Shepard, N. (1994), Partial non-Gaussian state space, Biometrika 81:115-131.

Stock, James H. and Mark W. Watson (1991), A probability model of the coincident economic indicators, in Kajal Lahiri and Geoffrey H. Moore, eds., Leading Economic Indicators: New Approaches and Forecasting Records, (Cambridge University Press, Cambridge, U.K.).

U.S. Department of Labor, Bureau of Labor Statistics (2004), Current population survey 19902003 employment adjusted for population controls, available at at www.bls.gov/cps/cpspopsm.pdf 
(March 2, 2004).

van Dijk, D., T. Terasvirta, and P.H. Franses (2002), Smooth transition autoregressive models: A survey of recent developments, Econometric Reviews 21:1-47. 


\section{Figure legends}

Figure 1. U.S. real GDP growth rates, 1947-2004.

Figure 2. Top panel: nonparametric estimate of the density of U.S. annualized growth rates for those postwar U.S. quarters classified by NBER as falling in recessions. Bottom panel: density for expansions.

Figure 3. Determining the probability of a recession from GDP growth rate alone. Top panel: probability of observing given GDP growth during expansions or contractions. Bottom panel: probability of being in a contraction having observed specified value for GDP growth.

Figure 4. Determining the probability of a recession when previous quarter gave a strong recession signal. Top panel: probability of observing given GDP growth in quarter $t+1$ given probability of recession of 0.90 in quarter $t$. Bottom panel: probability of being in a contraction in quarter $t+1$ given previous quarter's probability of 0.90 and having observed specified value for GDP growth in quartert +1 .

Figure 5. Probability of being in a recession based on one quarter's GDP data alone (top panel) and based on two quarter's GDP growth rates (bottom panel).

Figure 6. Probability that the U.S. economy is in recession based on revised quarterly data. Top panel: filter probabilities (inference using only GDP growth rates available at the time). Bottom panel: smoothed probabilities (inference using the full historical record). Shaded regions: dates of recessions as determined by NBER up to two years after the fact.

Figure 7. Probability that the U.S. economy is in recession. Top panel: one-quarter smoothed probabilities based on data as released historically as of two quarters after the indicated date

(e.g., the entry for 2003:I is based on GDP growth rates for 2003:II as reported in August 2003). Bottom panel: one-quarter smoothed probabilities based on historically revised data as reported for all quarters in August 2004.

Figure 8. Full-sample smoothed probabilities and NBER recessions based on revised monthly 
data.

Figure 9. Current filter probabilities and NBER recessions based on real-time monthly data after 1977:12 and revised monthly data before 1977:12.

Figure 10. Current filtered probabilities and h-month-smoothed probabilities of recession $(\mathrm{h}=1$, 2,3 ) based on real-time monthly data.

Figure 11. Filtered and smoothed probabilities with real-time monthly data over recursive samples. Top panel: 1980 and 1981-82 recessions. Middle panel: 1990-1991 recession. Bottom panel: 2001 recession. 


\section{Tables}

Table 1

Parameter estimates based on (1) characteristics of expansions and recessions as classified by NBER, and (2) values that maximize the observed sample log likelihood of postwar GDP growth rates

Parameter

Interpretation

$\begin{array}{cr}\mu_{1} & \text { average growth in expansion } \\ \mu_{2} & \text { average growth in recession } \\ \sigma & \text { standard deviation of growth } \\ p_{11} & \text { prob. expansion continues } \\ p_{22} & \text { prob. recession continues }\end{array}$

Value from NBER

classifications

$$
4.5
$$$$
-1.2
$$

0.95

0.78
Value from GDP alone

4.62

$-0.48$

3.34

0.92

0.74 


\section{Table 2}

Dates of recessions as determined by (1) NBER and (2) properties of GDP growth alone

\begin{tabular}{|c|c|c|c|}
\hline \multicolumn{2}{|c|}{ Start of recession } & \multicolumn{2}{|c|}{ End of recession } \\
\hline NBER & Smoothed probabilities & NBER & Smoothed probabilities \\
\hline 1948:IV & 1948:IV & 1949:IV & 1949:IV \\
\hline 1953:II & 1953:III & 1954:II & 1954:II \\
\hline 1957:III & 1957:II & 1958:II & 1958:I \\
\hline 1960:II & 1960:II & 1961:I & 1960:IV \\
\hline 1969:IV & 1969:III & 1970:IV & 1970:IV \\
\hline 1973:IV & 1973:III & 1975:I & 1975:I \\
\hline 1980:I & 1979:II & 1980:III & 1980:III \\
\hline 1981:III & 1981:II & 1982:IV & 1982:IV \\
\hline 1990:III & 1990:II & 1991:I & 1991:II \\
\hline 2001:I & 2000:IV & 2001:IV & $2001: I V$ \\
\hline
\end{tabular}


Table 3

Real-time GDP-based recession probability index and proposed announcements. Note: index and announcements are not released until 5 months after the end of the indicated quarter.

\begin{tabular}{|c|c|c|}
\hline Quarter $(t)$ & $q_{t}$ & $D_{t}$ \\
\hline $1967: I V$ & 4 & expansion \\
\hline 1968:I & 2 & expansion \\
\hline 1968:II & 1 & expansion \\
\hline 1968:III & 2 & expansion \\
\hline 1968:IV & 6 & expansion \\
\hline 1969:I & 13 & expansion \\
\hline 1969:II & 20 & expansion \\
\hline 1969:III & 46 & expansion \\
\hline 1969:IV & 89 & recession \\
\hline 1970:I & 98 & recession \\
\hline 1970:II & 92 & recession \\
\hline 1970:III & 95 & recession \\
\hline 1970:IV & 95 & recession \\
\hline 1971:I & 16 & expansion \\
\hline 1971:II & 10 & expansion \\
\hline 1971:III & 12 & expansion \\
\hline $1971:$ IV & 4 & expansion \\
\hline 1972:I & 1 & expansion \\
\hline 1972:II & 0 & expansion \\
\hline 1972:III & 1 & expansion \\
\hline 1972:IV & 0 & expansion \\
\hline 1973:I & 1 & expansion \\
\hline 1973:II & 10 & expansion \\
\hline 1973:III & 20 & expansion \\
\hline 1973:IV & 72 & recession \\
\hline 1974:I & 100 & recession \\
\hline 1974:II & 99 & recession \\
\hline 1974:III & 99 & recession \\
\hline 1974:IV & 100 & recession \\
\hline 1975:I & 100 & recession \\
\hline 1975:II & 43 & recession \\
\hline 1975:III & 0 & expansion \\
\hline 1975:IV & 0 & expansion \\
\hline 1976:I & 0 & expansion \\
\hline 1976:II & 1 & expansion \\
\hline 1976:III & 2 & expansion \\
\hline 1976:IV & 2 & expansion \\
\hline 1977:I & 0 & expansion \\
\hline
\end{tabular}

\begin{tabular}{|c|c|c|}
\hline 1977:II & 0 & expansion \\
\hline 1977:III & 1 & expansion \\
\hline 1977:IV & 7 & expansion \\
\hline 1978:I & 12 & expansion \\
\hline 1978:II & 0 & expansion \\
\hline 1978:III & 2 & expansion \\
\hline 1978:IV & 1 & expansion \\
\hline 1979:I & 49 & expansion \\
\hline 1979:II & 70 & recession \\
\hline 1979:III & 40 & recession \\
\hline 1979:IV & 39 & recession \\
\hline 1980:I & 82 & recession \\
\hline 1980:II & 100 & recession \\
\hline 1980:III & 37 & recession \\
\hline 1980:IV & 7 & expansion \\
\hline 1981:I & 2 & expansion \\
\hline 1981:II & 60 & expansion \\
\hline 1981:III & 79 & recession \\
\hline 1981:IV & 99 & recession \\
\hline 1982:I & 99 & recession \\
\hline 1982:II & 79 & recession \\
\hline 1982:III & 92 & recession \\
\hline 1982:IV & 85 & recession \\
\hline 1983:I & 32 & expansion \\
\hline 1983:II & 1 & expansion \\
\hline 1983:III & 0 & expansion \\
\hline 1983:IV & 1 & expansion \\
\hline 1984:I & 0 & expansion \\
\hline 1984:II & 1 & expansion \\
\hline 1984:III & 7 & expansion \\
\hline 1984:IV & 7 & expansion \\
\hline 1985:I & 30 & expansion \\
\hline 1985:II & 19 & expansion \\
\hline 1985:III & 17 & expansion \\
\hline 1985:IV & 27 & expansion \\
\hline 1986:I & 10 & expansion \\
\hline 1986:II & 20 & expansion \\
\hline 1986:III & 16 & expansion \\
\hline 1986:IV & 14 & expansion \\
\hline 1987:I & 7 & expansion \\
\hline 1987:II & 6 & expansion \\
\hline 1987:III & 2 & expansion \\
\hline 1987:IV & 2 & expansion \\
\hline 1988:I & 3 & expansion \\
\hline 1988:II & 5 & expansion \\
\hline
\end{tabular}




\begin{tabular}{|c|c|c|}
\hline 1988:III & 8 & expansion \\
\hline 1988:IV & 4 & expansion \\
\hline 1989:I & 5 & expansion \\
\hline 1989:II & 6 & expansion \\
\hline 1989:III & 9 & expansion \\
\hline 1989:IV & 12 & expansion \\
\hline 1990:I & 29 & expansion \\
\hline 1990:II & 41 & expansion \\
\hline 1990:III & 80 & recession \\
\hline 1990:IV & 95 & recession \\
\hline 1991:I & 97 & recession \\
\hline 1991:II & 90 & recession \\
\hline $1991:$ III & 81 & recession \\
\hline 1991:IV & 78 & recession \\
\hline 1992:I & 63 & recession \\
\hline 1992:II & 54 & recession \\
\hline 1992:III & 24 & expansion \\
\hline 1992:IV & 14 & expansion \\
\hline 1993:I & 35 & expansion \\
\hline 1993:II & 21 & expansion \\
\hline 1993:III & 8 & expansion \\
\hline 1993:IV & 3 & expansion \\
\hline 1994:I & 4 & expansion \\
\hline 1994:II & 4 & expansion \\
\hline 1994:III & 3 & expansion \\
\hline 1994:IV & 3 & expansion \\
\hline 1995:I & 12 & expansion \\
\hline 1995:II & 10 & expansion \\
\hline 1995:III & 33 & expansion \\
\hline 1995:IV & 33 & expansion \\
\hline 1996:I & 21 & expansion \\
\hline 1996:II & 11 & expansion \\
\hline 1996:III & 8 & expansion \\
\hline 1996:IV & 5 & expansion \\
\hline
\end{tabular}

\begin{tabular}{|c|c|c|}
\hline 1997:I & 4 & expansion \\
\hline 1997:II & 4 & expansion \\
\hline 1997:III & 4 & expansion \\
\hline 1997:IV & 4 & expansion \\
\hline 1998:I & 3 & expansion \\
\hline 1998:II & 6 & expansion \\
\hline 1998:III & 3 & expansion \\
\hline 1998:IV & 1 & expansion \\
\hline 1999:I & 2 & expansion \\
\hline 1999:II & 5 & expansion \\
\hline 1999:III & 1 & expansion \\
\hline 1999:IV & 0 & expansion \\
\hline 2000:I & 1 & expansion \\
\hline 2000:II & 1 & expansion \\
\hline 2000:III & 8 & expansion \\
\hline 2000:IV & 16 & expansion \\
\hline 2001:I & 27 & expansion \\
\hline 2001:II & 58 & expansion \\
\hline 2001:III & 84 & recession \\
\hline $2001: I V$ & 36 & recession \\
\hline 2002:I & 23 & expansion \\
\hline 2002:II & 20 & expansion \\
\hline 2002:III & 17 & expansion \\
\hline 2002:IV & 22 & expansion \\
\hline 2003:I & 24 & expansion \\
\hline 2003:II & 6 & expansion \\
\hline 2003:III & 1 & expansion \\
\hline 2003:IV & 2 & expansion \\
\hline 2004:I & 3 & expansion \\
\hline
\end{tabular}


Table 4

Dates at which recession starts and ends were announced by NBER and would have been announced using the one-quarter smoothed inferences from real-time released data.

\begin{tabular}{|l|l|l|l|l|l|}
\hline \multicolumn{3}{|l|}{ Start of recession } & \multicolumn{3}{c|}{ End of recession } \\
\hline $\begin{array}{l}\text { Start as } \\
\text { determined by } \\
\text { NBER }\end{array}$ & $\begin{array}{l}\text { Date start } \\
\text { announced by } \\
\text { NBER }\end{array}$ & $\begin{array}{l}\text { Date start } \\
\text { announced by } \\
\text { algorithm }\end{array}$ & $\begin{array}{l}\text { End as } \\
\text { determined by } \\
\text { NBER }\end{array}$ & $\begin{array}{l}\text { Date end } \\
\text { announced by } \\
\text { NBER }\end{array}$ & $\begin{array}{l}\text { Date end } \\
\text { announced by } \\
\text { algorithm }\end{array}$ \\
\hline 1969:IV & N.A. & May 1970 & 1970:IV & N.A. & Aug 1971 \\
\hline 1973:IV & N.A. & May 1974 & $1975:$ I & N.A. & Feb 1976 \\
\hline 1980:I & June 1980 & Nov 1979 & 1980:III & July 1981 & May 1981 \\
\hline 1981:III & Jan 1982 & Feb 1982 & 1982:IV & July 1983 & Aug 1983 \\
\hline 1990:III & April 1991 & Feb 1991 & 1991:I & Dec 1992 & Feb 1993 \\
\hline 2001:I & Nov 2001 & Feb 2002 & 2001:IV & July 2003 & Aug 2002 \\
\hline
\end{tabular}




\section{Table 5}

Parameter estimates and asymptotic standard errors based on values that maximize the observed sample log likelihood of the multivariate monthly model

\begin{tabular}{|c|c|c|c|}
\hline Parameter & $\begin{array}{l}\text { Estimate } \\
\text { (std error) }\end{array}$ & Parameter & $\begin{array}{l}\text { Estimate } \\
\text { (std error) }\end{array}$ \\
\hline$\alpha^{(1)}$ & $\begin{array}{c}0.95 \\
(0.18)\end{array}$ & $\lambda_{1}$ & $\begin{array}{c}0.33 \\
(0.028)\end{array}$ \\
\hline$\alpha^{(2)}$ & $\begin{array}{c}-0.4 \\
(0.24)\end{array}$ & $\lambda_{2}$ & $\begin{array}{c}0.23 \\
(0.015)\end{array}$ \\
\hline$\phi$ & $\begin{array}{c}0.37 \\
(0.07)\end{array}$ & $\lambda_{3}$ & $\begin{array}{c}0.12 \\
(0.009)\end{array}$ \\
\hline$\theta_{1}$ & $\begin{array}{l}-0.30 \\
(0.04)\end{array}$ & $\lambda_{4}$ & $\begin{array}{c}0.37 \\
(0.03)\end{array}$ \\
\hline$\theta_{2}$ & $\begin{array}{c}-0.029 \\
(0.06)\end{array}$ & $\sigma_{\varepsilon_{1}}^{2}$ & $\begin{array}{c}0.74 \\
(0.05)\end{array}$ \\
\hline$\theta_{3}$ & $\begin{array}{c}-0.021 \\
(0.05)\end{array}$ & $\sigma_{\varepsilon_{2}}^{2}$ & $\begin{array}{c}0.08 \\
(0.008)\end{array}$ \\
\hline$\theta_{4}$ & $\begin{array}{l}-0.19 \\
(0.05)\end{array}$ & $\sigma_{\varepsilon 3}^{2}$ & $\begin{array}{c}0.07 \\
(0.005)\end{array}$ \\
\hline$p_{11}$ & $\begin{array}{c}0.97 \\
(0.01)\end{array}$ & $\sigma_{\varepsilon 4}^{2}$ & $\begin{array}{c}0.33 \\
(0.027)\end{array}$ \\
\hline$p_{22}$ & $\begin{array}{c}0.90 \\
(0.05)\end{array}$ & $\ln f\left(\mathbf{Y}_{T}\right)$ & -1594.61 \\
\hline
\end{tabular}


Table 6

Dates of recessions as determined by (1) NBER and (2) Multivariate Markov-Switching Model (MMS) based on full-sample smoothed probabilities with revised monthly data

\begin{tabular}{|l|l|l|l|}
\hline \multicolumn{2}{|c|}{ Start of recession } & \multicolumn{2}{c|}{ End of Recession } \\
\hline NBER & $\begin{array}{l}\text { Smoothed probabilities } \\
\text { MMS }\end{array}$ & NBER & $\begin{array}{l}\text { Smoothed probabilities } \\
\text { MMS }\end{array}$ \\
\hline Apr 1960 & Feb 1960 & Feb 1961 & Dec 1960 \\
\hline Dec 1969 & Nov 1969 & Nov 1970 & Nov 1970 \\
\hline Nov 1973 & Dec 1973 & Mar 1975 & Mar 1975 \\
\hline Jan 1980 & Jan 1980 & Jul 1980 & Jun 1980 \\
\hline Jul 1981 & Aug 1981 & Nov 1982 & Nov 1982 \\
\hline Jul 1990 & May 1990 & Mar 1991 & Feb 1991 \\
\hline Mar 2001 & Sept 2000 & Nov 2001 & Oct 2001 \\
\hline
\end{tabular}


Table 7

Monthly real-time multiple-indicator recession probability index and proposed announcements. Note: preliminary index released 2 months after the indicated month; revised index and determination are not released until 3 months after the indicated month.

\begin{tabular}{|c|c|c|c|}
\hline & Preliminary & Revised & Determination \\
\hline Month $(t)$ & Index $\left(p_{t}^{(m)}\right)$ & Index $\left(q_{t}^{(m)}\right)$ & $\left(D_{t}^{(m)}\right)$ \\
\hline Nov 1977 & 1 & 1 & expansion \\
\hline Dec 1977 & 1 & 20 & expansion \\
\hline Jan 1978 & 57 & 23 & expansion \\
\hline Feb 1978 & 8 & 1 & expansion \\
\hline Mar 1978 & 0 & 0 & expansion \\
\hline Apr 1978 & 0 & 0 & expansion \\
\hline May 1978 & 2 & 1 & expansion \\
\hline Jun 1978 & 1 & 2 & expansion \\
\hline Jul 1978 & 8 & 3 & expansion \\
\hline Aug 1978 & 3 & 2 & expansion \\
\hline Sep 1978 & 2 & 1 & expansion \\
\hline Oct 1978 & 1 & 0 & expansion \\
\hline Nov 1978 & 1 & 0 & expansion \\
\hline Dec 1978 & 1 & 3 & expansion \\
\hline Jan 1979 & 8 & 4 & expansion \\
\hline Feb 1979 & 3 & 1 & expansion \\
\hline Mar 1979 & 1 & 22 & expansion \\
\hline Apr 1979 & 77 & 48 & expansion \\
\hline May 1979 & 21 & 15 & expansion \\
\hline Jun 1979 & 13 & 16 & expansion \\
\hline Jul 1979 & 16 & 39 & expansion \\
\hline Aug 1979 & 41 & 31 & expansion \\
\hline Sep 1979 & 24 & 10 & expansion \\
\hline Oct 1979 & 6 & 5 & expansion \\
\hline Nov 1979 & 5 & 3 & expansion \\
\hline Dec 1979 & 3 & 2 & expansion \\
\hline Jan 1980 & 3 & 10 & expansion \\
\hline Feb 1980 & 17 & 79 & expansion \\
\hline Mar 1980 & 88 & 100 & recession \\
\hline Apr 1980 & 100 & 100 & recession \\
\hline May 1980 & 99 & 100 & recession \\
\hline Jun 1980 & 90 & 90 & recession \\
\hline Jul 1980 & 75 & 41 & recession \\
\hline
\end{tabular}

\begin{tabular}{|c|c|c|c|}
\hline Aug 1980 & 14 & 3 & expansion \\
\hline Sep 1980 & 0 & 0 & expansion \\
\hline Oct 1980 & 0 & 0 & expansion \\
\hline Nov 1980 & 0 & 0 & expansion \\
\hline Dec 1980 & 2 & 9 & expansion \\
\hline Jan 1981 & 19 & 34 & expansion \\
\hline Feb 1981 & 35 & 22 & expansion \\
\hline Mar 1981 & 16 & 24 & expansion \\
\hline Apr 1981 & 24 & 11 & expansion \\
\hline May 1981 & 7 & 8 & expansion \\
\hline Jun 1981 & 9 & 2 & expansion \\
\hline Jul 1981 & 1 & 1 & expansion \\
\hline Aug 1981 & 4 & 31 & expansion \\
\hline Sep 1981 & 49 & 85 & expansion \\
\hline Oct 1981 & 85 & 97 & recession \\
\hline Nov 1981 & 94 & 99 & recession \\
\hline Dec 1981 & 96 & 99 & recession \\
\hline Jan 1982 & 97 & 85 & recession \\
\hline Feb 1982 & 77 & 60 & recession \\
\hline Mar 1982 & 70 & 58 & recession \\
\hline Apr 1982 & 58 & 43 & recession \\
\hline May 1982 & 80 & 83 & recession \\
\hline Jun 1982 & 82 & 94 & recession \\
\hline Jul 1982 & 90 & 95 & recession \\
\hline Aug 1982 & 89 & 93 & recession \\
\hline Sep 1982 & 84 & 96 & recession \\
\hline Oct 1982 & 94 & 94 & recession \\
\hline Nov 1982 & 81 & 81 & recession \\
\hline Dec 1982 & 70 & 28 & recession \\
\hline Jan 1983 & 3 & 8 & expansion \\
\hline Feb 1983 & 13 & 3 & expansion \\
\hline Mar 1983 & 1 & 0 & expansion \\
\hline Apr 1983 & 1 & 0 & expansion \\
\hline May 1983 & 1 & 0 & expansion \\
\hline Jun 1983 & 0 & 0 & expansion \\
\hline
\end{tabular}




\begin{tabular}{|c|c|c|c|}
\hline Jul 1983 & 0 & 0 & expansion \\
\hline Aug 1983 & 3 & 1 & expansion \\
\hline Sep 1983 & 0 & 0 & expansion \\
\hline Oct 1983 & 0 & 0 & expansion \\
\hline Nov 1983 & 1 & 0 & expansion \\
\hline Dec 1983 & 0 & 0 & expansion \\
\hline Jan 1984 & 0 & 0 & expansion \\
\hline Feb 1984 & 2 & 1 & expansion \\
\hline Mar 1984 & 1 & 0 & expansion \\
\hline Apr 1984 & 1 & 0 & expansion \\
\hline May 1984 & 1 & 0 & expansion \\
\hline Jun 1984 & 1 & 1 & expansion \\
\hline Jul 1984 & 2 & 4 & expansion \\
\hline Aug 1984 & 7 & 5 & expansion \\
\hline Sep 1984 & 5 & 6 & expansion \\
\hline Oct 1984 & 8 & 3 & expansion \\
\hline Nov 1984 & 2 & 1 & expansion \\
\hline Dec 1984 & 2 & 4 & expansion \\
\hline Jan 1985 & 8 & 5 & expansion \\
\hline Feb 1985 & 4 & 2 & expansion \\
\hline Mar 1985 & 2 & 3 & expansion \\
\hline Apr 1985 & 7 & 5 & expansion \\
\hline May 1985 & 6 & 14 & expansion \\
\hline Jun 1985 & 18 & 49 & expansion \\
\hline Jul 1985 & 53 & 19 & expansion \\
\hline Aug 1985 & 5 & 2 & expansion \\
\hline Sep 1985 & 1 & 1 & expansion \\
\hline Oct 1985 & 3 & 4 & expansion \\
\hline Nov 1985 & 5 & 1 & expansion \\
\hline Dec 1985 & 1 & 1 & expansion \\
\hline Jan 1986 & 3 & 5 & expansion \\
\hline Feb 1986 & 9 & 6 & expansion \\
\hline Mar 1986 & 6 & 3 & expansion \\
\hline Apr 1986 & 3 & 3 & expansion \\
\hline May 1986 & 5 & 5 & expansion \\
\hline Jun 1986 & 7 & 3 & expansion \\
\hline Jul 1986 & 2 & 2 & expansion \\
\hline Aug 1986 & 3 & 2 & expansion \\
\hline
\end{tabular}

\begin{tabular}{|c|c|c|c|}
\hline Sep 1986 & 2 & 3 & expansion \\
\hline Oct 1986 & 5 & 4 & expansion \\
\hline Nov 1986 & 4 & 1 & expansion \\
\hline Dec 1986 & 1 & 6 & expansion \\
\hline Jan 1987 & 19 & 4 & expansion \\
\hline Feb 1987 & 1 & 0 & expansion \\
\hline Mar 1987 & 2 & 2 & expansion \\
\hline Apr 1987 & 3 & 1 & expansion \\
\hline May 1987 & 1 & 1 & expansion \\
\hline Jun 1987 & 3 & 1 & expansion \\
\hline Jul 1987 & 1 & 0 & expansion \\
\hline Aug 1987 & 1 & 1 & expansion \\
\hline Sep 1987 & 4 & 1 & expansion \\
\hline Oct 1987 & 1 & 0 & expansion \\
\hline Nov 1987 & 2 & 1 & expansion \\
\hline Dec 1987 & 1 & 3 & expansion \\
\hline Jan 1988 & 12 & 4 & expansion \\
\hline Feb 1988 & 2 & 2 & expansion \\
\hline Mar 1988 & 3 & 2 & expansion \\
\hline Apr 1988 & 2 & 4 & expansion \\
\hline May 1988 & 8 & 3 & expansion \\
\hline Jun 1988 & 2 & 1 & expansion \\
\hline Jul 1988 & 2 & 2 & expansion \\
\hline Aug 1988 & 3 & 6 & expansion \\
\hline Sep 1988 & 9 & 3 & expansion \\
\hline Oct 1988 & 2 & 1 & expansion \\
\hline Nov 1988 & 2 & 1 & expansion \\
\hline Dec 1988 & 1 & 0 & expansion \\
\hline Jan 1989 & 1 & 3 & expansion \\
\hline Feb 1989 & 11 & 10 & expansion \\
\hline Mar 1989 & 10 & 13 & expansion \\
\hline Apr 1989 & 15 & 54 & expansion \\
\hline May 1989 & 60 & 43 & expansion \\
\hline Jun 1989 & 30 & 70 & expansion \\
\hline Jul 1989 & 72 & 34 & expansion \\
\hline Aug 1989 & 7 & 22 & expansion \\
\hline Sep 1989 & 27 & 33 & expansion \\
\hline Oct 1989 & 31 & 10 & expansion \\
\hline
\end{tabular}




\begin{tabular}{|c|c|c|c|}
\hline Nov 1989 & 4 & 2 & expansion \\
\hline Dec 1989 & 3 & 3 & expansion \\
\hline Jan 1990 & 6 & 2 & expansion \\
\hline Feb 1990 & 1 & 1 & expansion \\
\hline Mar 1990 & 3 & 4 & expansion \\
\hline Apr 1990 & 8 & 11 & expansion \\
\hline May 1990 & 13 & 9 & expansion \\
\hline Jun 1990 & 9 & 13 & expansion \\
\hline Jul 1990 & 14 & 25 & expansion \\
\hline Aug 1990 & 26 & 61 & expansion \\
\hline Sep 1990 & 63 & 96 & expansion \\
\hline Oct 1990 & 96 & 99 & recession \\
\hline Nov 1990 & 94 & 96 & recession \\
\hline Dec 1990 & 88 & 98 & recession \\
\hline Jan 1991 & 96 & 97 & recession \\
\hline Feb 1991 & 85 & 87 & recession \\
\hline Mar 1991 & 77 & 43 & recession \\
\hline Apr 1991 & 15 & 8 & expansion \\
\hline May 1991 & 7 & 2 & expansion \\
\hline Jun 1991 & 1 & 3 & expansion \\
\hline Jul 1991 & 7 & 11 & expansion \\
\hline Aug 1991 & 13 & 4 & expansion \\
\hline Sep 1991 & 2 & 8 & expansion \\
\hline Oct 1991 & 16 & 19 & expansion \\
\hline Nov 1991 & 19 & 36 & expansion \\
\hline Dec 1991 & 37 & 30 & expansion \\
\hline Jan 1992 & 25 & 7 & expansion \\
\hline Feb 1992 & 2 & 1 & expansion \\
\hline Mar 1992 & 2 & 1 & expansion \\
\hline Apr 1992 & 1 & 2 & expansion \\
\hline May 1992 & 4 & 4 & expansion \\
\hline Jun 1992 & 6 & 2 & expansion \\
\hline Jul 1992 & 2 & 12 & expansion \\
\hline Aug 1992 & 27 & 12 & expansion \\
\hline Sep 1992 & 7 & 2 & expansion \\
\hline Oct 1992 & 2 & 1 & expansion \\
\hline Nov 1992 & 2 & 2 & expansion \\
\hline Dec 1992 & 5 & 2 & expansion \\
\hline
\end{tabular}

\begin{tabular}{|c|c|c|c|}
\hline Jan 1993 & 2 & 2 & expansion \\
\hline Feb 1993 & 4 & 12 & expansion \\
\hline Mar 1993 & 17 & 4 & expansion \\
\hline Apr 1993 & 0 & 0 & expansion \\
\hline May 1993 & 3 & 3 & expansion \\
\hline Jun 1993 & 5 & 5 & expansion \\
\hline Jul 1993 & 7 & 4 & expansion \\
\hline Aug 1993 & 4 & 4 & expansion \\
\hline Sep 1993 & 6 & 2 & expansion \\
\hline Oct 1993 & 2 & 1 & expansion \\
\hline Nov 1993 & 2 & 1 & expansion \\
\hline Dec 1993 & 1 & 2 & expansion \\
\hline Jan 1994 & 5 & 2 & expansion \\
\hline Feb 1994 & 1 & 0 & expansion \\
\hline Mar 1994 & 1 & 0 & expansion \\
\hline Apr 1994 & 1 & 0 & expansion \\
\hline May 1994 & 1 & 1 & expansion \\
\hline Jun 1994 & 3 & 5 & expansion \\
\hline Jul 1994 & 7 & 2 & expansion \\
\hline Aug 1994 & 1 & 1 & expansion \\
\hline Sep 1994 & 2 & 0 & expansion \\
\hline Oct 1994 & 1 & 0 & expansion \\
\hline Nov 1994 & 2 & 1 & expansion \\
\hline Dec 1994 & 1 & 1 & expansion \\
\hline Jan 1995 & 2 & 4 & expansion \\
\hline Feb 1995 & 8 & 12 & expansion \\
\hline Mar 1995 & 14 & 24 & expansion \\
\hline Apr 1995 & 26 & 36 & expansion \\
\hline May 1995 & 35 & 16 & expansion \\
\hline Jun 1995 & 9 & 17 & expansion \\
\hline Jul 1995 & 19 & 5 & expansion \\
\hline Aug 1995 & 1 & 1 & expansion \\
\hline Sep 1995 & 1 & 2 & expansion \\
\hline Oct 1995 & 6 & 3 & expansion \\
\hline Nov 1995 & 3 & 2 & expansion \\
\hline Dec 1995 & 3 & 14 & expansion \\
\hline Jan 1996 & 25 & 5 & expansion \\
\hline Feb 1996 & 1 & 1 & expansion \\
\hline
\end{tabular}




\begin{tabular}{|c|c|c|c|}
\hline Mar 1996 & 3 & 1 & expansion \\
\hline Apr 1996 & 2 & 1 & expansion \\
\hline May 1996 & 1 & 0 & expansion \\
\hline Jun 1996 & 1 & 1 & expansion \\
\hline Jul 1996 & 5 & 2 & expansion \\
\hline Aug 1996 & 1 & 1 & expansion \\
\hline Sep 1996 & 1 & 1 & expansion \\
\hline Oct 1996 & 3 & 1 & expansion \\
\hline Nov 1996 & 1 & 1 & expansion \\
\hline $\operatorname{Dec} 1996$ & 3 & 5 & expansion \\
\hline Jan 1997 & 9 & 2 & expansion \\
\hline Feb 1997 & 1 & 1 & expansion \\
\hline Mar 1997 & 1 & 1 & expansion \\
\hline Apr 1997 & 2 & 1 & expansion \\
\hline May 1997 & 2 & 1 & expansion \\
\hline Jun 1997 & 2 & 1 & expansion \\
\hline Jul 1997 & 1 & 0 & expansion \\
\hline Aug 1997 & 1 & 1 & expansion \\
\hline Sep 1997 & 2 & 1 & expansion \\
\hline Oct 1997 & 1 & 0 & expansion \\
\hline Nov 1997 & 1 & 1 & expansion \\
\hline Dec 1997 & 2 & 1 & expansion \\
\hline Jan 1998 & 1 & 0 & expansion \\
\hline Feb 1998 & 1 & 1 & expansion \\
\hline Mar 1998 & 1 & 1 & expansion \\
\hline Apr 1998 & 2 & 1 & expansion \\
\hline May 1998 & 2 & 3 & expansion \\
\hline Jun 1998 & 6 & 10 & expansion \\
\hline Jul 1998 & 13 & 3 & expansion \\
\hline Aug 1998 & 1 & 0 & expansion \\
\hline Sep 1998 & 2 & 1 & expansion \\
\hline Oct 1998 & 2 & 1 & expansion \\
\hline Nov 1998 & 2 & 2 & expansion \\
\hline Dec 1998 & 3 & 2 & expansion \\
\hline Jan 1999 & 2 & 1 & expansion \\
\hline Feb 1999 & 2 & 2 & expansion \\
\hline Mar 1999 & 4 & 8 & expansion \\
\hline Apr 1999 & 12 & 4 & expansion \\
\hline
\end{tabular}

\begin{tabular}{|c|c|c|c|}
\hline May 1999 & 2 & 2 & expansion \\
\hline Jun 1999 & 3 & 2 & expansion \\
\hline Jul 1999 & 3 & 1 & expansion \\
\hline Aug 1999 & 1 & 4 & expansion \\
\hline Sep 1999 & 10 & 2 & expansion \\
\hline Oct 1999 & 1 & 0 & expansion \\
\hline Nov 1999 & 1 & 0 & expansion \\
\hline Dec 1999 & 1 & 0 & expansion \\
\hline Jan 2000 & 0 & 0 & expansion \\
\hline Feb 2000 & 2 & 2 & expansion \\
\hline Mar 2000 & 3 & 1 & expansion \\
\hline Apr 2000 & 2 & 3 & expansion \\
\hline May 2000 & 8 & 5 & expansion \\
\hline Jun 2000 & 5 & 5 & expansion \\
\hline Jul 2000 & 7 & 9 & expansion \\
\hline Aug 2000 & 10 & 7 & expansion \\
\hline Sep 2000 & 7 & 11 & expansion \\
\hline Oct 2000 & 13 & 26 & expansion \\
\hline Nov 2000 & 29 & 38 & expansion \\
\hline Dec 2000 & 36 & 60 & expansion \\
\hline Jan 2001 & 60 & 66 & expansion \\
\hline Feb 2001 & 59 & 75 & expansion \\
\hline Mar 2001 & 71 & 92 & recession \\
\hline Apr 2001 & 90 & 96 & recession \\
\hline May 2001 & 90 & 94 & recession \\
\hline Jun 2001 & 87 & 81 & recession \\
\hline Jul 2001 & 60 & 76 & recession \\
\hline Aug 2001 & 72 & 91 & recession \\
\hline Sep 2001 & 89 & 78 & recession \\
\hline Oct 2001 & 52 & 61 & recession \\
\hline Nov 2001 & 56 & 58 & recession \\
\hline Dec 2001 & 52 & 53 & recession \\
\hline Jan 2002 & 46 & 26 & recession \\
\hline Feb 2002 & 17 & 27 & expansion \\
\hline Mar 2002 & 28 & 14 & expansion \\
\hline Apr 2002 & 10 & 5 & expansion \\
\hline May 2002 & 4 & 3 & expansion \\
\hline Jun 2002 & 3 & 7 & expansion \\
\hline
\end{tabular}




\begin{tabular}{|l|r|r|l|}
\hline Jul 2002 & 12 & 12 & expansion \\
\hline Aug 2002 & 12 & 20 & expansion \\
\hline Sep 2002 & 22 & 43 & expansion \\
\hline Oct 2002 & 44 & 48 & expansion \\
\hline Nov 2002 & 43 & 75 & expansion \\
\hline Dec 2002 & 75 & 39 & expansion \\
\hline Jan 2003 & 11 & 17 & expansion \\
\hline Feb 2003 & 18 & 35 & expansion \\
\hline Mar 2003 & 37 & 30 & expansion \\
\hline Apr 2003 & 24 & 14 & expansion \\
\hline May 2003 & 11 & 9 & expansion \\
\hline
\end{tabular}

\begin{tabular}{|l|r|r|l|}
\hline Jun 2003 & 9 & 3 & expansion \\
\hline Jul 2003 & 2 & 2 & expansion \\
\hline Aug 2003 & 5 & 3 & expansion \\
\hline Sep 2003 & 3 & 2 & expansion \\
\hline Oct 2003 & 2 & 1 & expansion \\
\hline Nov 2003 & 1 & 1 & expansion \\
\hline Dec 2003 & 4 & 3 & expansion \\
\hline Jan 2004 & 4 & 4 & expansion \\
\hline
\end{tabular}


Table 8

Dates of recession as determined by (1) NBER and in real time by (2) multivariate Markov-switching model estimated over recursive samples

\begin{tabular}{|c|c|c|c|c|c|}
\hline Start Date: NBER & $\begin{array}{c}\text { Start Date: MMS } \\
\text { Model }\end{array}$ & $\begin{array}{c}\text { Lead (+)/ Lag (-) } \\
\text { Discrepancy }\end{array}$ & $\begin{array}{c}\text { Start Date Announced: } \\
\text { NBER }\end{array}$ & $\begin{array}{c}\text { Start Date Available: } \\
\text { MMS Model }\end{array}$ & $\begin{array}{c}\text { Lead Announcement } \\
\text { Date of } \\
\text { MMS Model }\end{array}$ \\
\hline Jan 1980 & Mar 1980 & 2 months & Jun 3, 1980 & June 1980 \\
Jul 1981 & Oct 1981 & 3 months & Jan 6, 1982 & Jan 1982 \\
Jul 1990 & Oct 1990 & 3 months & Apr 25, 1991 & Jan 1991 \\
Mar 2001 & Mar 2001 & 0 months & Nov 26, 2001 & June 2001 \\
\hline
\end{tabular}

\begin{tabular}{|c|c|c|c|c|c|}
\hline End Date: NBER & End Date: MMS Model & $\begin{array}{c}\text { Lead (+)/ Lag (-) } \\
\text { Discrepancy }\end{array}$ & $\begin{array}{c}\text { End Date Announced: } \\
\text { NBER }\end{array}$ & $\begin{array}{c}\text { End Date Available: } \\
\text { MMS Model }\end{array}$ & $\begin{array}{c}\text { Lead Announcement } \\
\text { Date of MMS Model }\end{array}$ \\
\hline Jul 1980 & Jul 1980 & 0 months & Jul 8, 1981 & Nov 1980 \\
Nov 1982 & Dec 1982 & 1 month & Jul 8, 1983 & Apr 1983 months \\
Mar 1991 & Mar 1991 & D months & Dec 22, 1992 & Jul 1991 \\
Nov 2001 & Jan 2002 & 2 months & Jul 17, 2003 & May 2002 \\
\hline
\end{tabular}

Note: Leads or lags are represented by + or -, respectively, and indicate how many months the Markov switching model anticipates or lags the NBER dating, whereas 0 indicates that the two dating systems coincide. A business cycle downturn is announced when there are two succeeding months all with probabilities greater than 0.65 . An upturn is announced when there are two successive months with probabilities below 0.35 . 
Figure 1. U.S. real GDP growth rates, 1947-2004

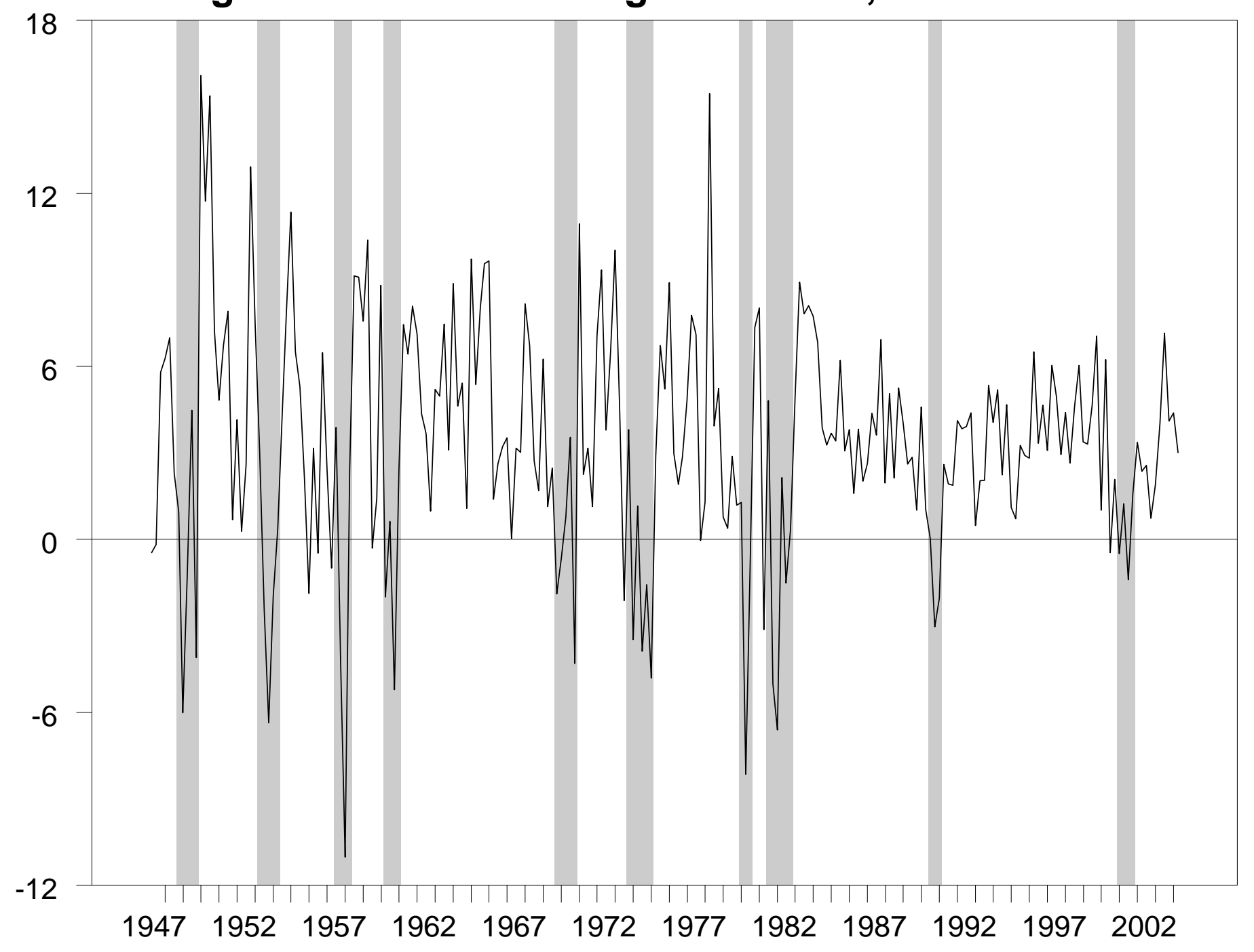


Figure 2

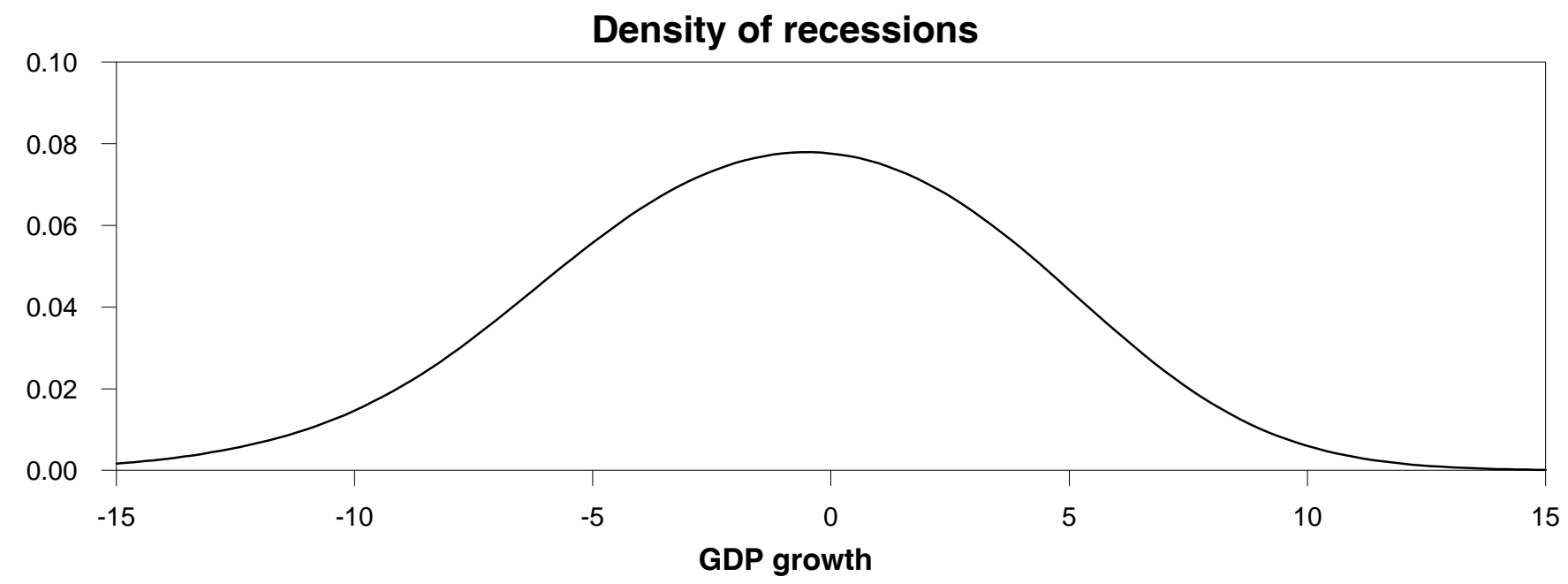

Density of expansions

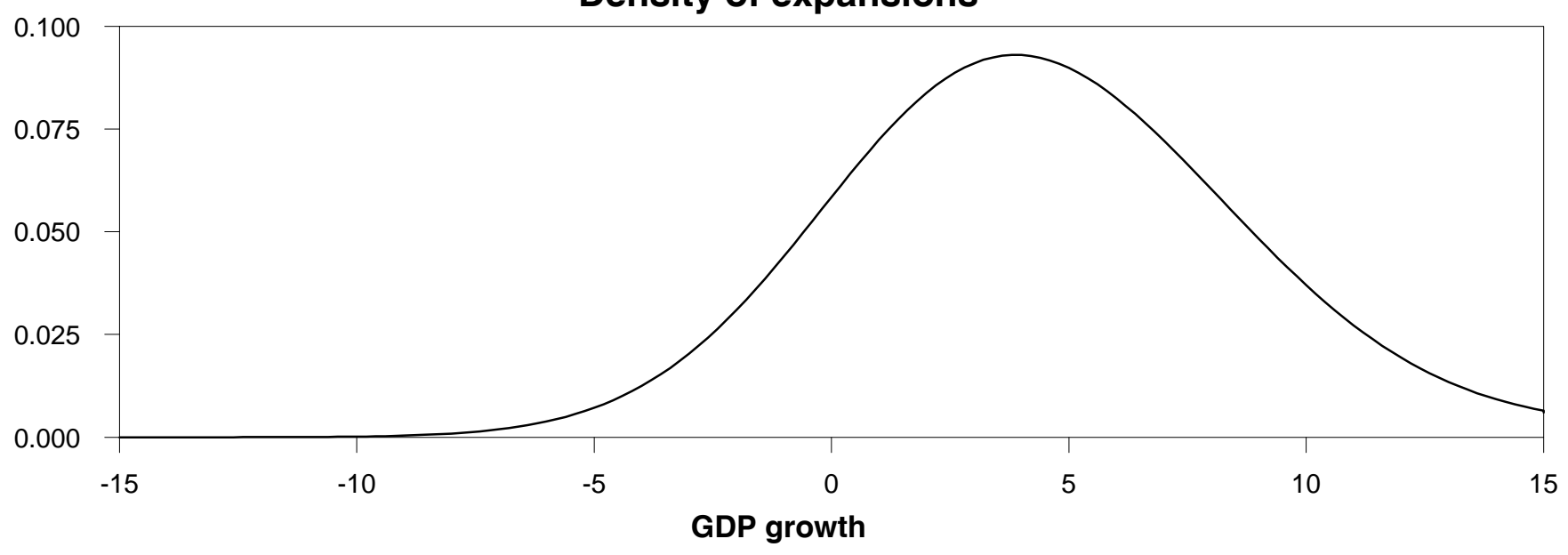




\section{Figure 3}
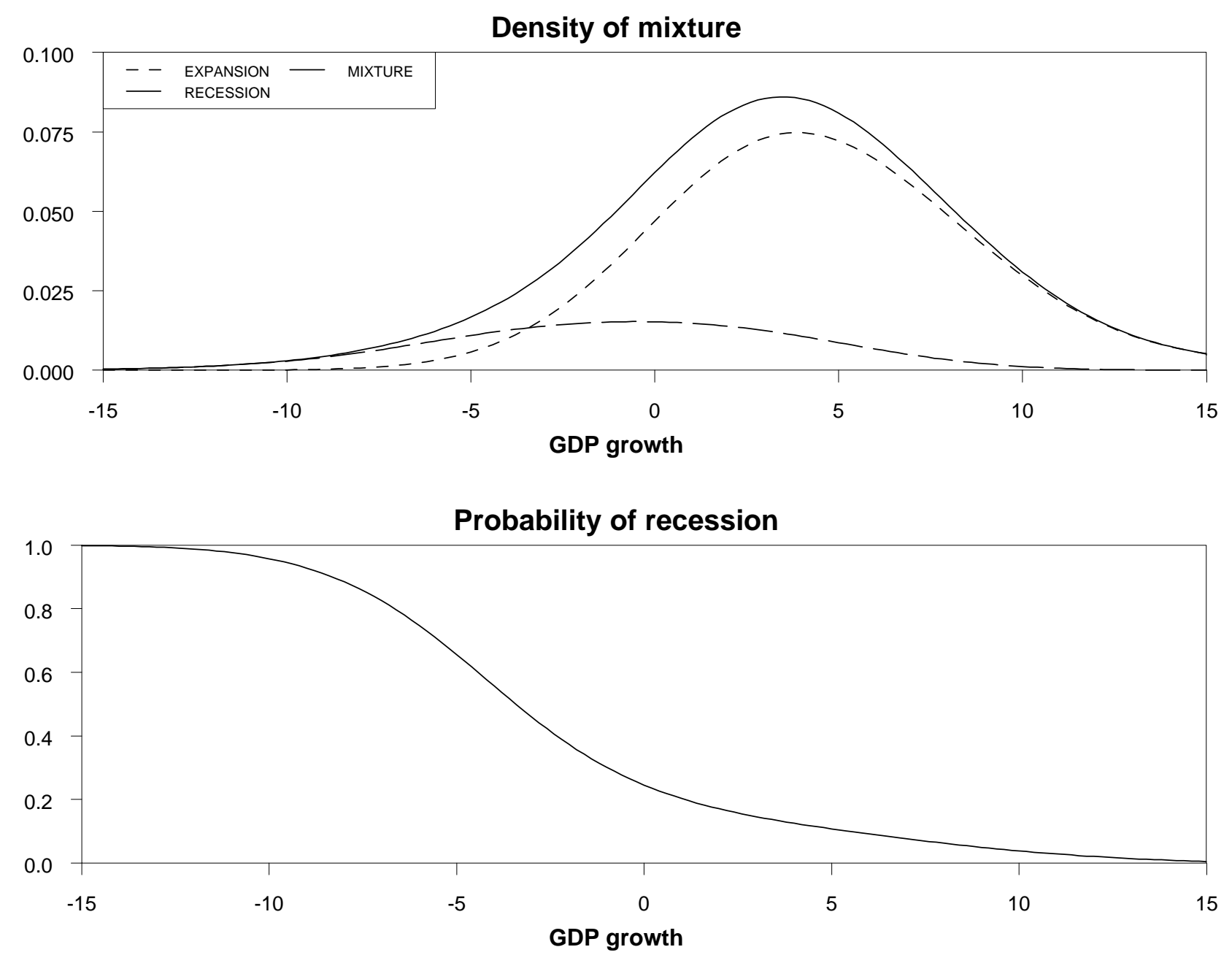


\section{Figure 4}
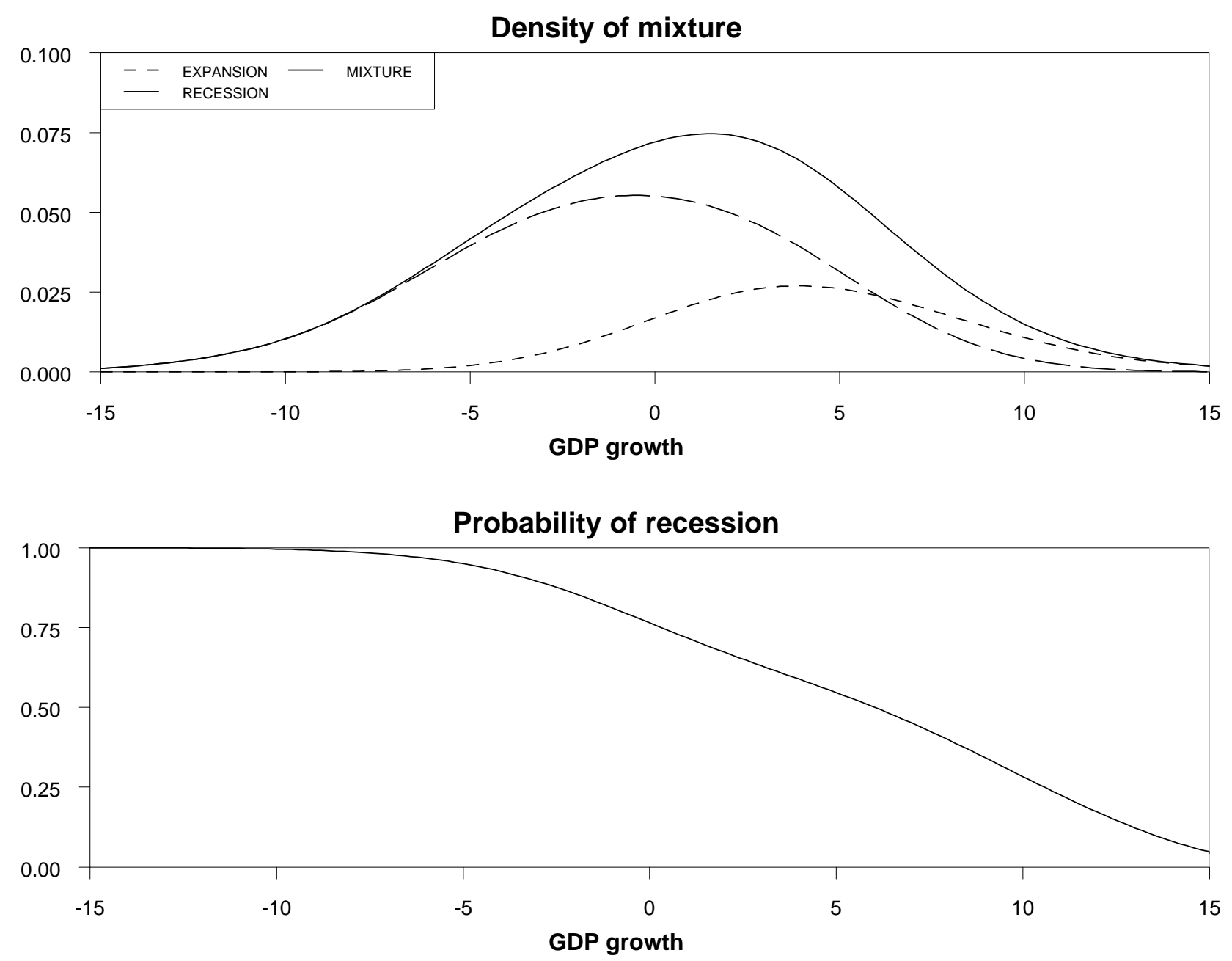
Figure 5
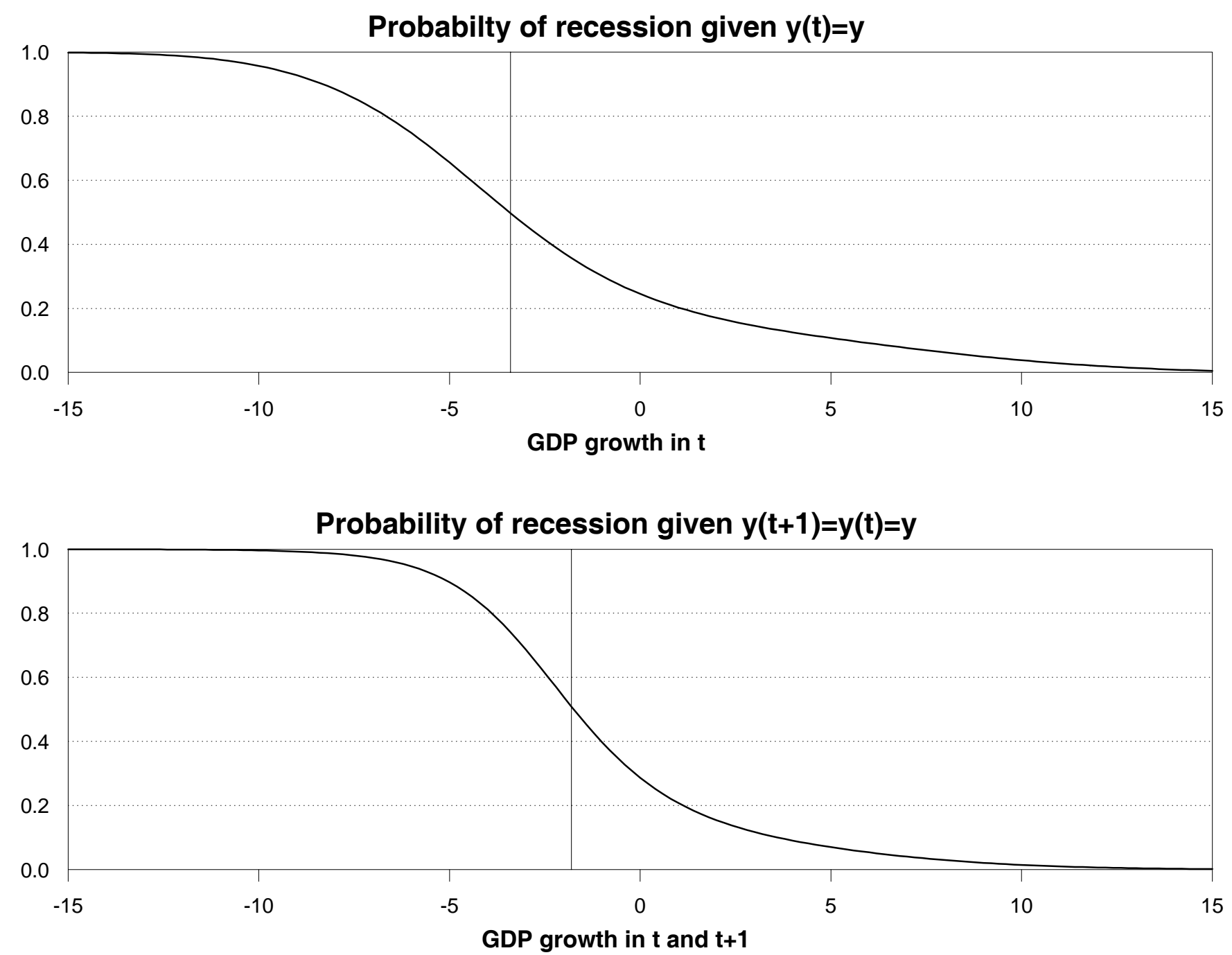


\section{Figure 6}

Probability that the U.S. economy is in recession based on revised quarterly data. Top panel: filter probabilities (inference using only GDP growth rates available at the time). Bottom panel: smoothed probabilities (inference using the full historical record). Shaded regions: dates of recessions as determined by NBER up to two years after the fact.
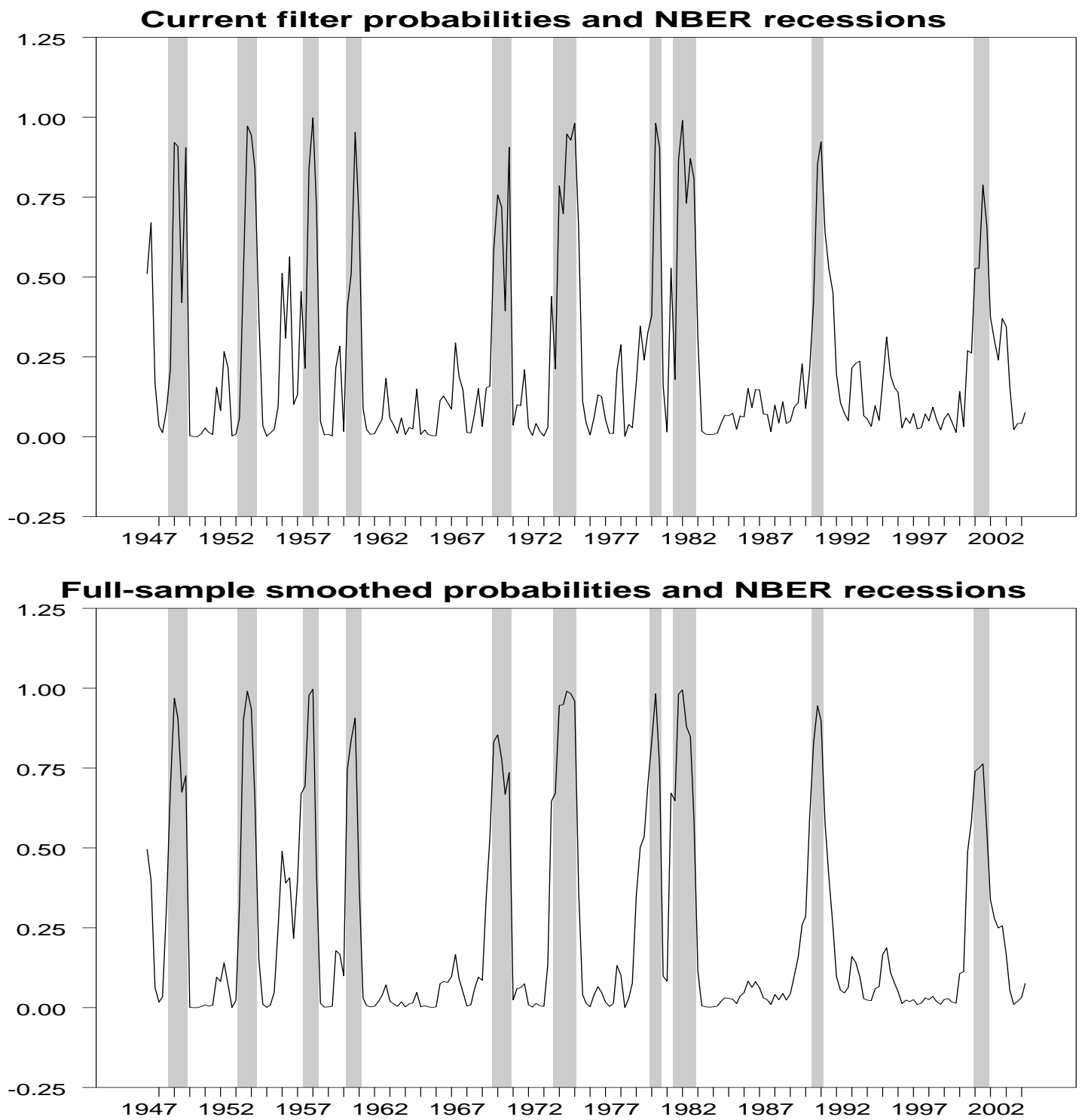


\section{Figure 7}

Probability that the U.S. economy is in recession. Top panel: one-quarter smoothed probabilities based on data as released historically as of two quarters after the indicated date (e.g., the entry for 2003:I is based on GDP growth rates for 2003:II as reported in August 2003). Bottom panel: one-quarter smoothed probabilities based on historically revised data as reported for all quarters in August 2004.
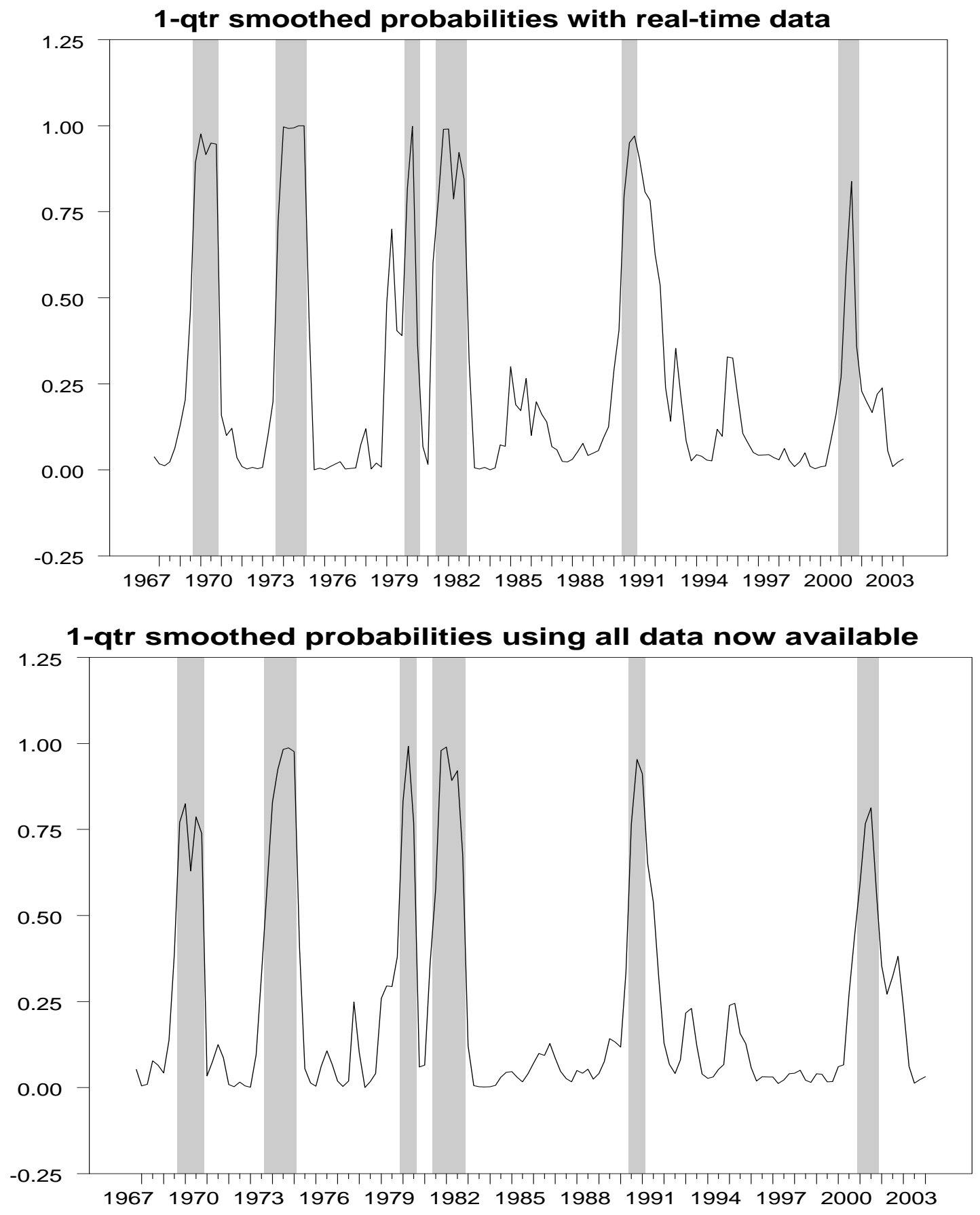
Figure 8

Full-sample smoothed probabilities and NBER recessions based on revised monthly data

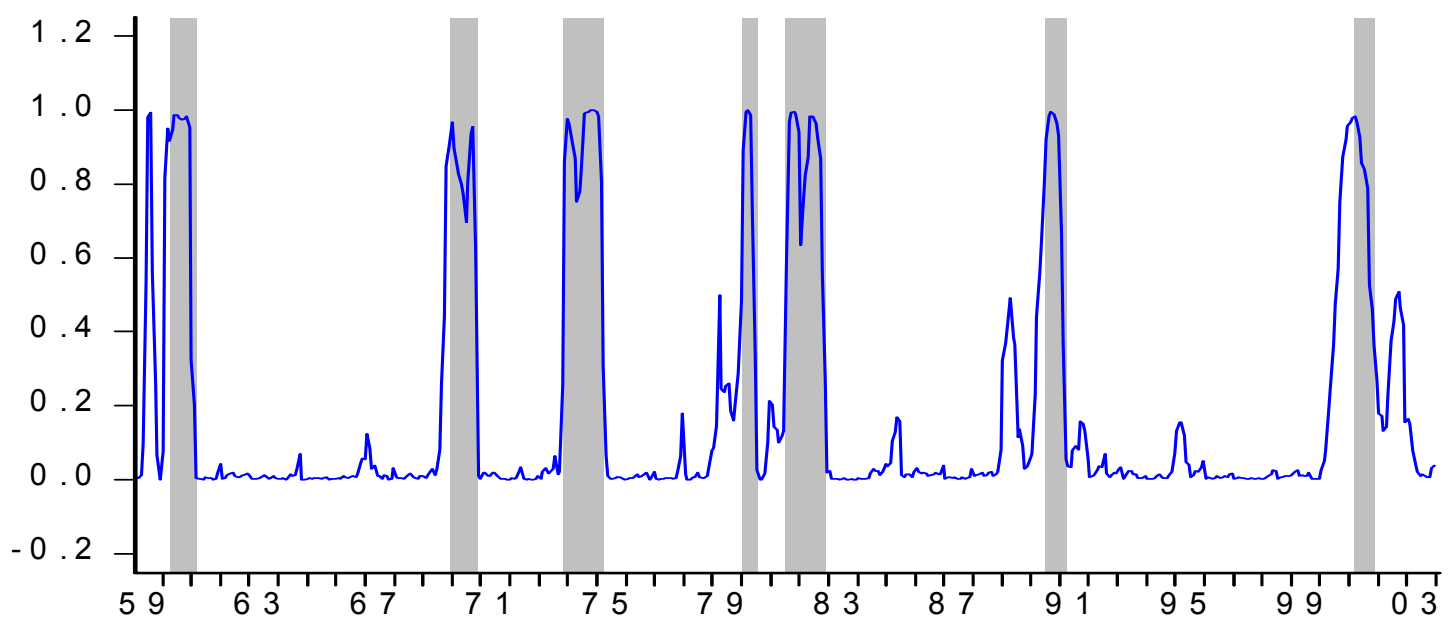


Figure 9

Current filter probabilities and NBER recessions based on real-time monthly data after 1977:12 and revised monthly data before 1977:12

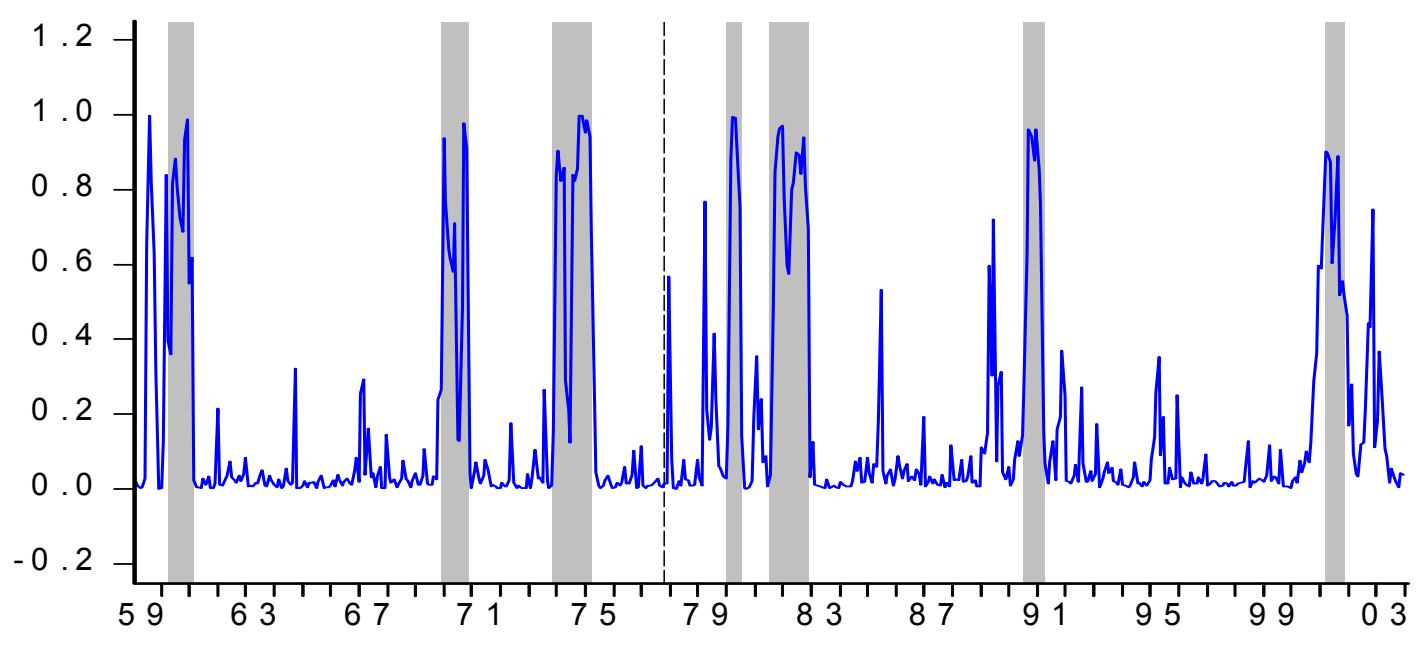


Figure 10

Current filtered probabilities and h-month-smoothed probabilities of recession $(\mathrm{h}=1,2,3)$ based on real-time monthly data
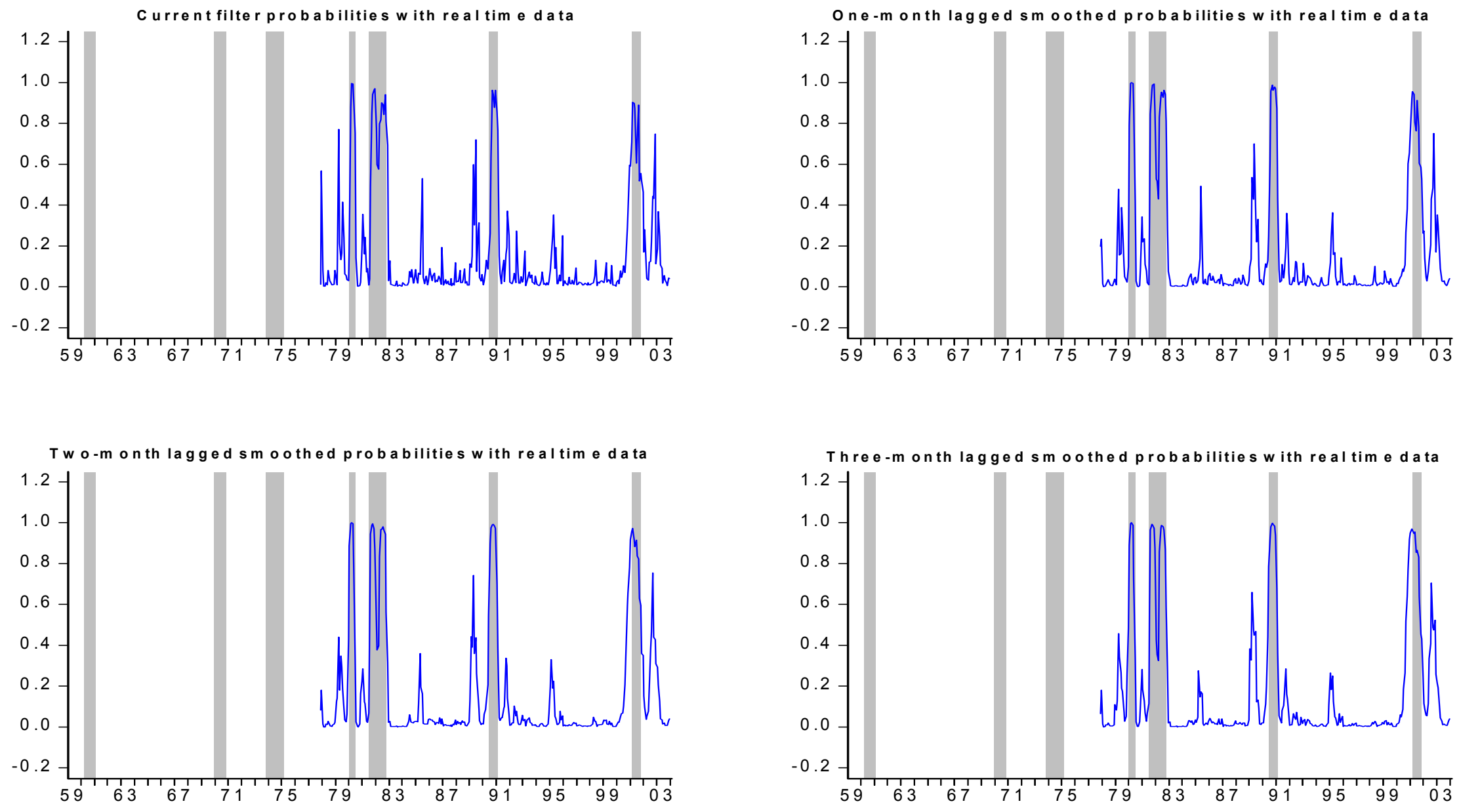
Figure 11

Filtered and smoothed probabilities with real-time monthly data over recursive samples

1980 and 1981-82 Recessions

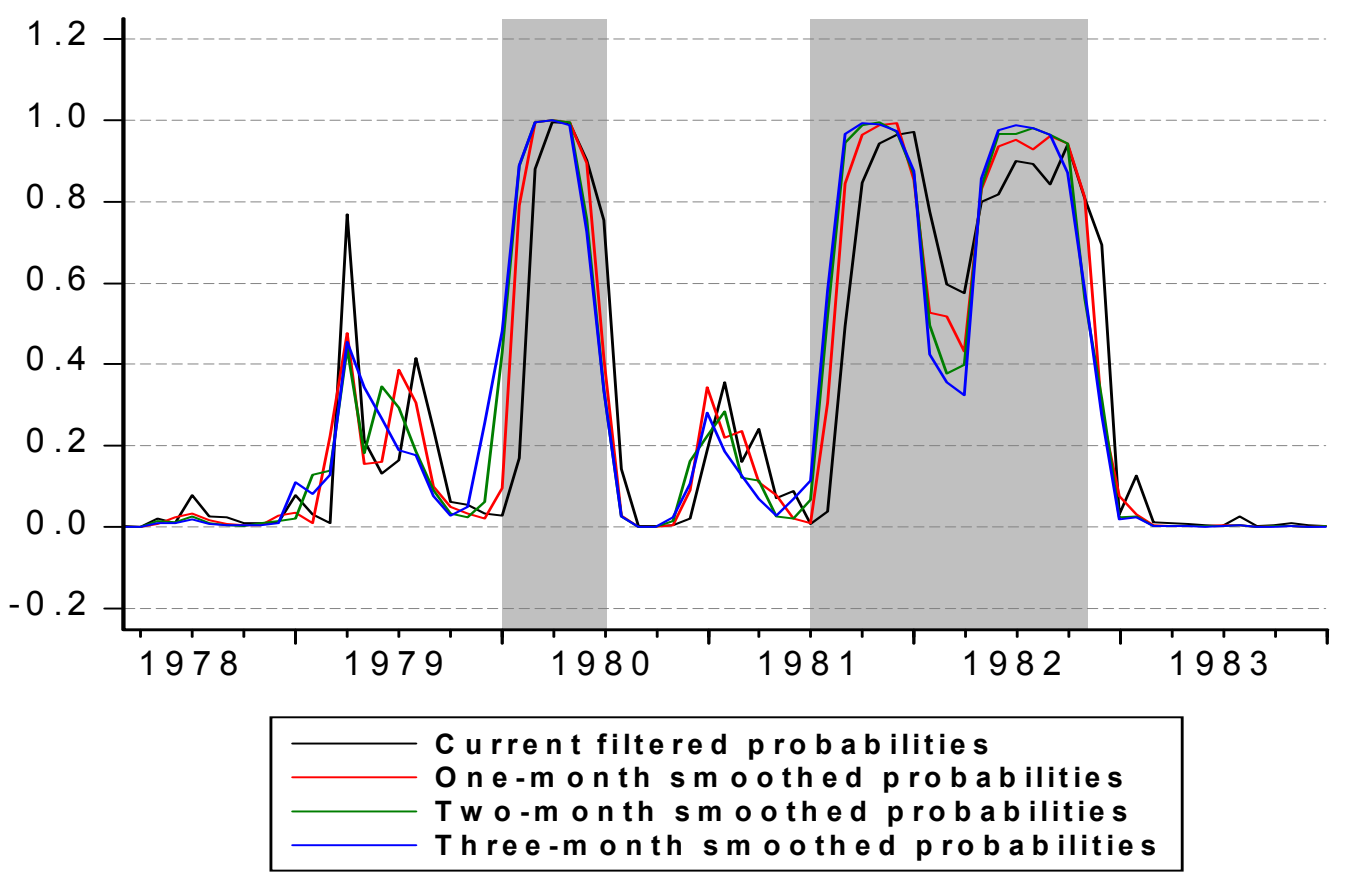

1990-1991 Recession

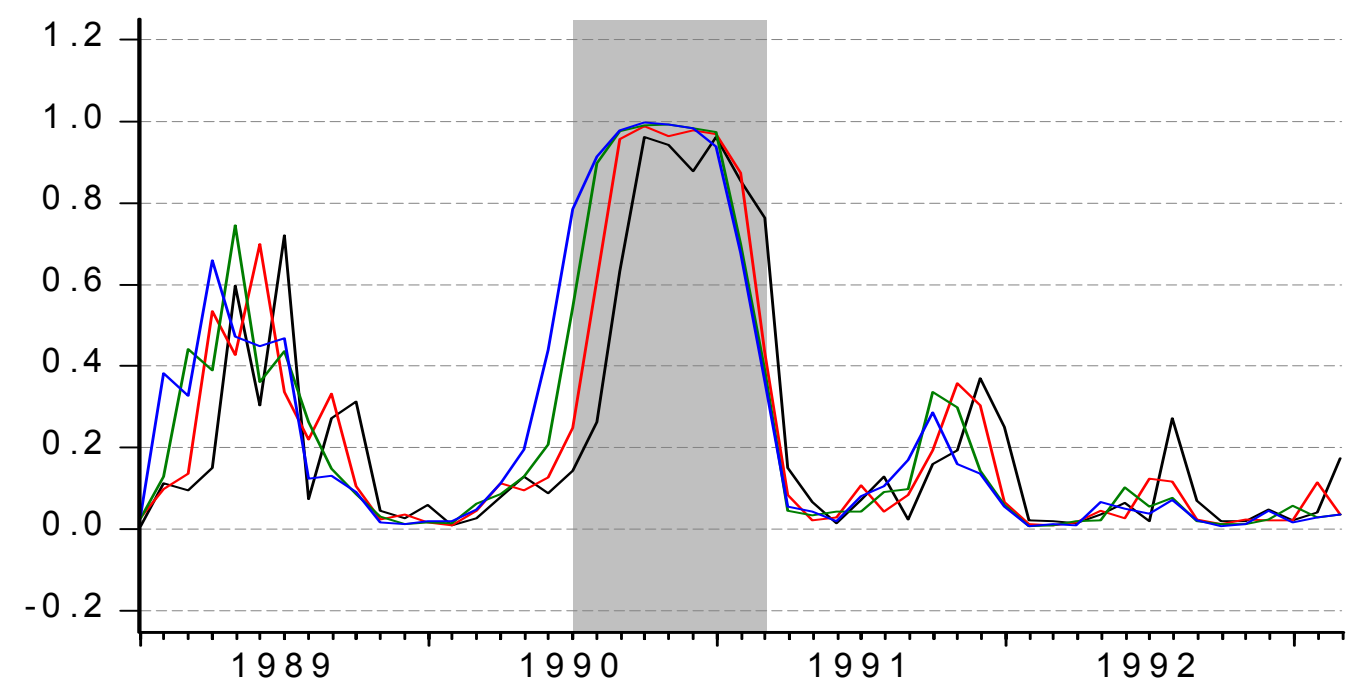

Current filtered probabilities

One-month smoothed probabilities

Two-month smoothed probabilities

Three-month smoothed probabilities 


\section{Recession}

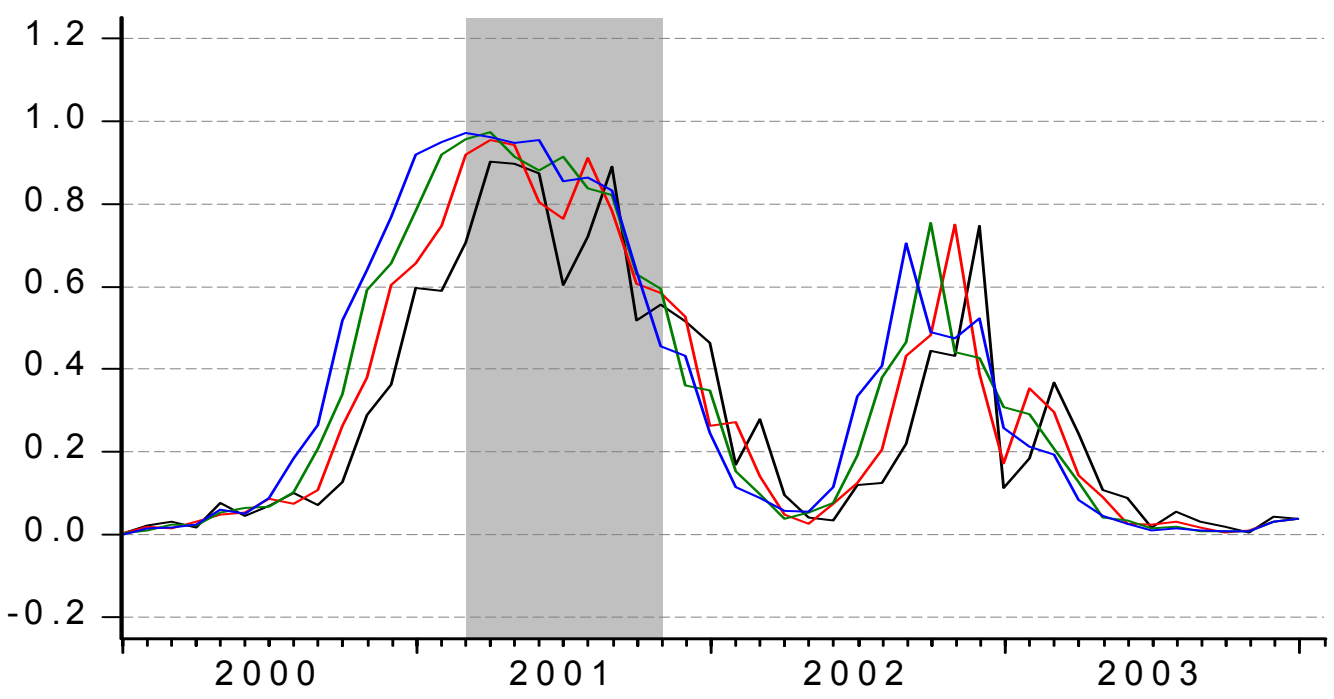

Current filtered probabilities One-month smoothed probabilities

Two-month smoothed probabilities

Three-month smoothed probabilities 